Florida International University FIU Digital Commons

\title{
The effectiveness of training educators on their ability to identify function of problem behavior
}

Charles Dukes

Florida International University

DOI: $10.25148 /$ etd.FI15101239

Follow this and additional works at: https://digitalcommons.fiu.edu/etd

Part of the Special Education and Teaching Commons

\section{Recommended Citation}

Dukes, Charles, "The effectiveness of training educators on their ability to identify function of problem behavior" (2002). FIU

Electronic Theses and Dissertations. 3096.

https://digitalcommons.fiu.edu/etd/3096 


\title{
FLORIDA INTERNATIONAL UNIVERSITY
}

\author{
Miami, Florida
}

THE EFFECTIVENESS OF TRAINING EDUCATORS ON THEIR ABILITY TO IDENTIFY FUNCTION OF PROBLEM BEHAVIOR

A dissertation submitted in partial fulfillment of the

requirements for the degree of

DOCTOR OF EDUCATION

in

EXCEPTIONAL STUDENT EDUCATION

by

Charles Dukes

2002 
To: Dean Linda Blanton

College of Education

This dissertation, written by Charles Dukes, and entitled The Effectiveness of Training Educators on Their Ability to Identify Function of Problem Behavior, having been approved in respect to style and intellectual content, is referred to you for judgment.

We have read this dissertation and recommend that it be approved.

Michael Brady

Barry Greenberg

Patricia del Valle

Howard Rosenberg, Major Professor

Date of Defense: July 22, 2002

The dissertation of Charles Dukes is approved.

Dean Linda Blanton College of Education

Florida International University, 2002 


\section{ACKNOWLEDGMENTS}

I wish to thank the members of my committee for their support and continued guidance throughout my writing process. Their collaborative work enabled me to achieve one of most important professional goals. I would like to thank Dr. Howard Rosenberg for taking on the all-important role of major professor. I would like to especially thank Dr. Michael Brady who has been a mentor throughout a majority of my career in education.

My experiences in the Educational and Psychological Studies Department have allowed me to explore some of the most fascinating aspects of the education field. 


\begin{abstract}
OF THE DISSERTATION
THE EFFECTIVENESS OF TRAINING EDUCATORS ON THEIR ABILITY TO

IDENTIFY FUNCTION OF PROBLEM BEHAVIOR

by
\end{abstract}

Charles Dukes

Florida International University, 2002

Miami, Florida

Professor Howard Rosenberg, Major Professor

The purpose of this study was to investigate the effectiveness of training

educators in the pre - behavioral intervention process of functional behavioral

assessment. An original evaluation instrument was developed entitled, The Survey for

Students Exhibiting Challenging Behavior. The instrument included measures of

participating educators, knowledge of function of problem behavior and their ability to

generate recommendations for a behavior intervention plan. The instrument was

distributed to schools in a large urban district and completed by special educators.

Educators trained and untrained in the functional behavioral assessment process were compared in the study.

The study incorporated a post - test only design. All instruments were analyzed using a factorial ANOVA. Those educators who were trained in the district functional 
behavioral assessment program answered general questions related to function of problem behavior significantly better than those who did not receive training. There is no significant difference between educators on their ability to generate recommendations for behavior intervention plans. It is important that educators receive training in functional behavioral assessment to gain an understanding of the basic notions being function of problem behavior. Current training does not translate into educators' ability to make strong recommendations for behavior intervention plans. 


\section{TABLE OF CONTENTS}

CHAPTER

PAGE

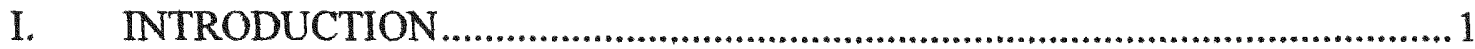

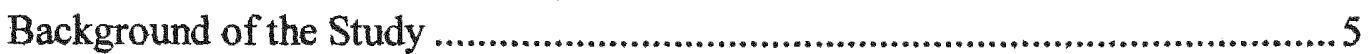

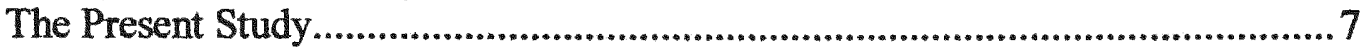

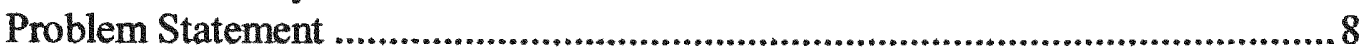

General Purpose of the Study........................................................................9

Research Questions ..............................................................................11

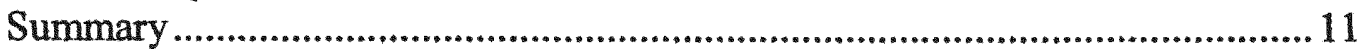

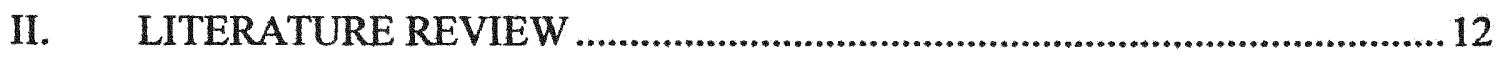

Federal Legislation Influencing the Field of Special Education........................ 12

A Movement toward a Technology of Behavior............................................... 14

Functional Assessment .......................................................................... 18

Purpose ...................................................................................................... 18

Determining the Function of Behavior............................................................ 19

Positive Behavioral Interventions .....................................................................23

Functional Assessment in Schools ................................................................26

Making Functional Assessment Work................................................................28

Evaluating Functional Assessment............................................................31

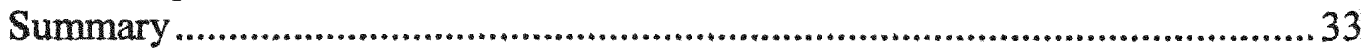

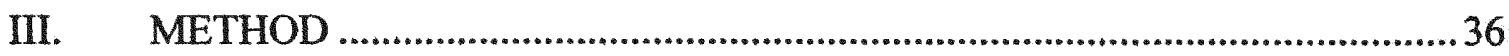

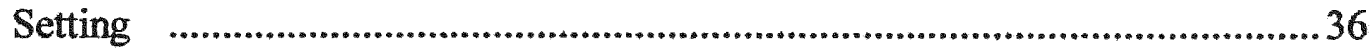

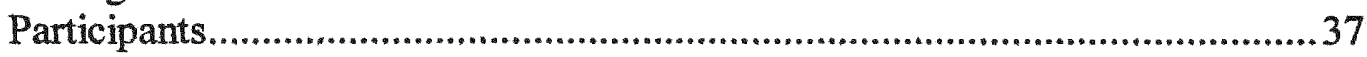

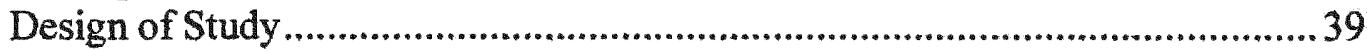

Data Analysis ................................................................................... 40

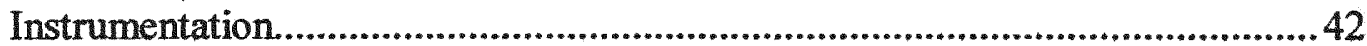

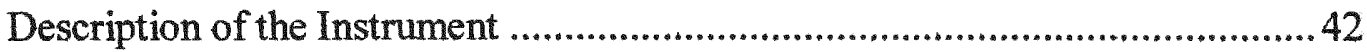

Knowledge of Function Items .........................................................................42

Recommendation Measurement .................................................................. 42

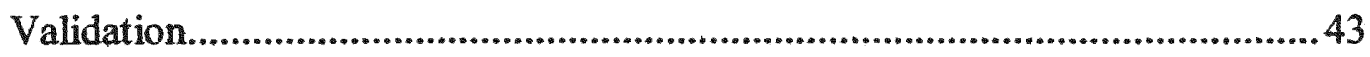

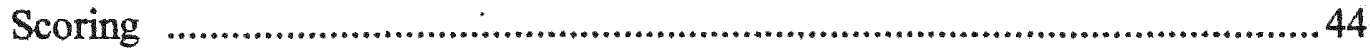

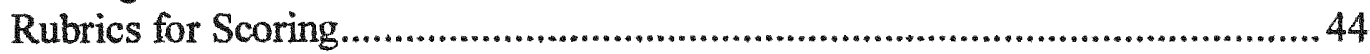

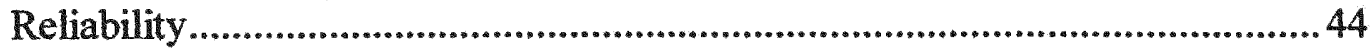

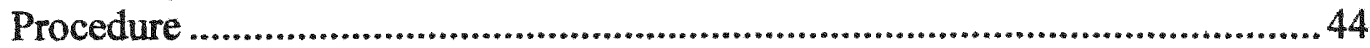

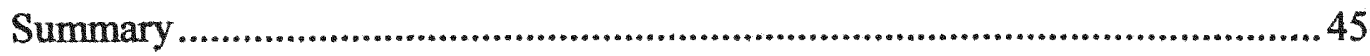

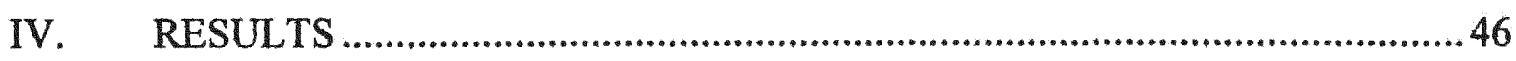

Demographics ................................................................................................ 46

Comparison of Trained and Untrained Participants ........................................... 46

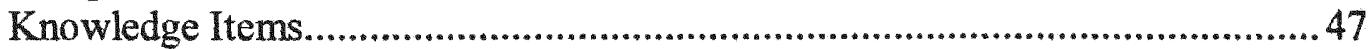

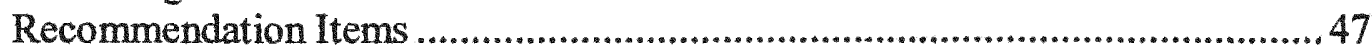


Analysis of Certification Status ...............................................................48

Training Status ...................................................................................... 48

Knowledge of Function and Recommendation

for Behavior Intervention Plan Items ........................................................49

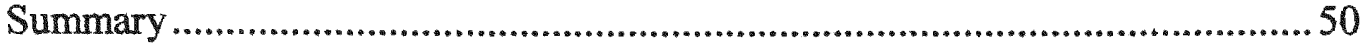

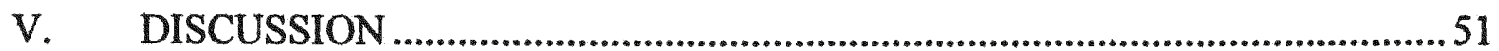

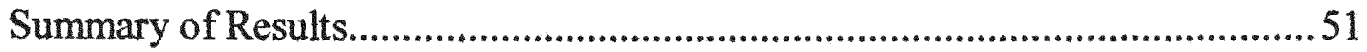

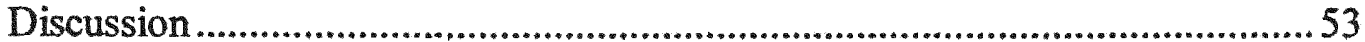

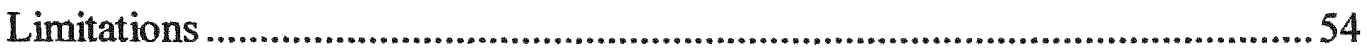

Implications for Practice.............................................................................5

Recommendations for Further Research...................................................556

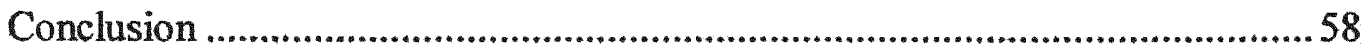

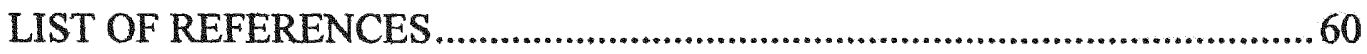

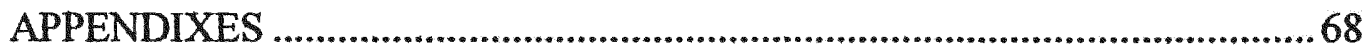

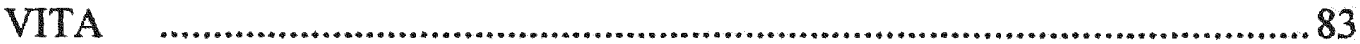




\section{LIST OF TABLES}

TABLE

PAGE

1. Student Demographics in M-DCPS ........................................................... 37

2. Grade Level and Training Status Comparison for Knowledge Items...................47

3. Grade Level and Training Status Comparison for Recommendation Items .........48 48

4. Certification and Training Status Comparison for Knowledge Items ................. 48

5. Certification and Training Status Comparison for Recommendation Items........49

6. Mean Scores According to Certification Status ................................................50 


\section{CHAPTER I}

\section{INTRODUCTION}

Public schools are charged with the task of providing a free and appropriate public education to a vastly diverse number of students. To provide quality services for children, school personnel must be able to provide an inclusive program considering a number of variables. Each public school program must include contingencies that address a number of problems, issues, and concerns for students, parents, teachers, administrators, and their surrounding communities. While the broad issues of "appropriate" education may be widely debated in the academic and political communities, schools have a basic purpose to teach children those skills necessary to function in society at large, and to develop and maintain a preferred quality of life. Public schools bring together a varied cross section of our society including a "sample" of varying personalities, skills, and deficits in social and academic areas. To serve this diverse population, schools must influence behavior. In this sense, school personnel are charged with introducing behavioral standards in academic and social arenas. In addition to the development of such standards school personnel must also develop and implement methodology to maintain students' behavior to enable them to accomplish long-term quality of life goals.

School personnel are under intense pressure to directly influence students to develop social and academic skills. As stated previously many students have varying abilities and thus some school programs may not be the best "fit" for all students. The majority of school programs are not tailored to individuals, but rather created with the 
intent of serving the majority in the same manner, in spite of their differences. While many school programs are highly similar, this does not imply that all schools are the same. Rather, the foundation of American schools is the same, thus practices may share some common characteristics, but each school does have unique qualities.

The similarity amongst American public schools emerges from an array of factors, one of which includes the pre - service university education program. Programs in pre - service university education as well as a number of other sources (e.g., in service teacher training, educational research) also have influence on educational practice. Educational practice is not an easily defined term. The "practices" pre-service and in - service teachers adopt may be influenced by training or research literature. There are also other outside influences on professional practice. These outside influences vary from the manner in which one was taught to the most popular method during a particular time period (Greenwood \& Abbott, 2001). It is the combination of all of these influences that direct the methods used with students in schools. Ayers (1994) reports that there is a tremendous discrepancy between what typically occurs for most students with disabilities in school and what the literature says should be occurring as exemplary practices. Many educators utilize non-empirically based practices, yet these same practices have been widely circulated in schools for a number of years. The design of seating arrangements, lesson plans, and exclusion for problem behavior, for example have remained the same for several generations.

The commonality that is pervasive among public schools is one of the challenges facing those who wish to provide effective educational programs that meet the needs of all students. In - service teachers draw from a widely accepted body of knowledge in 
relation to their "behavior" to build skills in students. In addition to the commonality of educational programs, professional development efforts do not necessarily influence "teacher behavior." The phrase "teacher behavior" refers to the instructional methods utilized by teachers to influence the development of social and academic skills. Teacher behavior also refers to the skills and methods one uses to manage classroom and school wide student behavior. Included in the "management" of classroom and school - wide behavior is the potential "problem behavior" exhibited by students in public schools.

The terms, problem behavior, maladaptive behavior, aberrant behavior, and challenging behavior are all used to describe those behaviors exhibited by students who do not follow the rules set forth in the school program. A great number of students exhibit problem behavior at one or several points during their public education experience. This problem behavior can have an adverse affect on teachers, parents, other students, and the student herself/himself.

Since problem behavior can have an adverse effect on the learning and physical safety of students and teachers, the action taken in response to problem behavior is worthy of critical review. While responses to problem behavior are common in nature, the alternatives are limited. Teachers have often viewed behavior as the responsibility of the administrator who is outside of the classroom. This view has lead many teachers to use a common or "default" response to a wide variety of problem behaviors: removal of the student.

Whether these problem behaviors are disruptive (e.g., talking out of turn, leaving one's seat, or leaving class without permission) or more threatening (e.g., physical altercation, stealing, or destroying property) educators must reduce or completely 
extinguish the behaviors. Teachers do engage in behavioral interventions at the classroom level, although, these interventions may at times be largely punitive in nature. In a recent study Ishii - Jordan (2000) found that teachers selected more punitive interventions (e.g., punishment, threats) for students with behaviors perceived as teacher - owned problems (i.e., behaviors that interfered with or threatened the teacher's needs).

The response to problem behavior is similar to the general guidelines used to construct the school program, in that one response is generally developed in spite of an individual's unique need. While many problem behaviors may have similar characteristics, it is insufficient to base an intervention on general notions of a diagnostic label or topography of the problem behavior devoid of an understanding about the individual or the behavior. The effect on students of these inadequate disciplinary techniques is documented by the fact that discipline problems are the major cause of student referrals made by general educators to special education (Zimmerman, 1998).

A common response to problem behavior is "exclusion" from the school program (i.e., suspension). In general, teachers have relinquished responsibility for the most challenging students to administrators. Suspension from school remains one of the most common administrative responses to school disciplinary problems at the secondary level. Intended as a punishment for a wide variety of disruptive and inappropriate behaviors, suspension consists of temporarily excluding the student from the regularly assigned academic environment. As a discipline procedure, suspensions are based on the premise that exclusion from class or school is an effective deterrent or punishment (Diem, 1988 as quoted in Morgan - D' Atrio et al. 1996). Punishment is the behavior used by all 
organisms to try to control one another, but its application to humans is fraught with unintended consequences (Maag, 2001).

The use of suspension to deter and ultimately influence behavior change in students who exhibit problem behavior is inadequate for students with and without disabilities. Suspensions do not significantly reduce serious or recurrent behavior problems for many students and may, in fact, exacerbate behavior problems (Morgan D'Atrio, et al. 1996). This may especially be true for students with disabilities. When students with disabilities are suspended or expelled, this process distupts their education. They are likely to fall further behind, become frustrated and, too frequently, drop out of school. Wagner (1991) found that $28 \%$ of students in special education with discipline problems cited those problems as the reasons for dropping out of school. About $4 \%$ of all students in special education are expelled and fail to graduate. In addition, Wager (1991) indicated that students with disabilities who are frequently suspended are more likely to fail classes that are required for graduation.

In spite of the current shortcomings of the current response to problem behavior, a point of reference must be made to the general intent of schools and teachers. Educational programs are established to impart academic and social skills. There are a number of questions for educators to ask themselves to better serve students with disabilities and mange problem behavior. How can one learn when excluded from the school program? Why is exclusion the popular choice when intervening for behavior change?

Background of the Study

To provide an answer to the questions posed above, one could examine school programs, teachers, administrators, or even parent responses to problem behaviors. 
Teachers specifically employ common response repertoire to problem behavior, even though teacher preparation programs are based on a number of philosophies and provide teachers - in - preparation with varied experiences. Within these preparation programs teachers acquire different methods in which to intervene with problem behavior. Despite the pre - service education and in - service training efforts, in practice, the common educational philosophy seems to be that "one size fits all." The transfer of research into classroom practice seems to be rare and when research findings do transfer, the quality of implementation is often poor (Gersten \& Brengleman, 1996). This reliance on non empirically based methods for behavior change can inhibit many students from fully participating in an educational program. When teachers perceive behavior as challenging, students with disabilities are denied opportunities to benefit from particular educational experiences (Foster - Johnson et al., 1993).

"One size fits all" is a common means to respond to problem behavior. This limited notion in relation to problem behavior response is inadequate and should be examined. However, current behavior change technology does influence positive change in many students with disabilities, although there are some concerns related to its effectiveness. As discussed by Fox et al. (1998), virtually every behavioral procedure has been shown to be effective in dealing with the challenging behaviors of some children but less effective with others. Second, behavioral gains may be lost when the intervention is removed. Third, it is not always apparent which of several behavioral procedures should be applied simply from an examination of the behavior itself.

Two factors have had an overwhelming influence on behavior change methods. The first change is in the reauthorization of the Individuals with Disabilities Acts of 1997 
(IDEA '97). The second change emerged from research on pre - intervention methods. The research conducted by Carr (1977) and Iwata et al. (1982) shifted the of behavioral intervention research from a focus on discipline toward a focus on the functional analysis of behavior.

Each of the changes has influenced professional practice in education and psychology. Educators are bound by the requirements contained in the IDEA ' 97 . The policies were developed in direct relation to the advancements made in the research laboratories of those researching in the field of applied behavior analysis. This body of research has had a particular influence in public education. While Nelson and his colleagues (1999) have argued that the policy (i.e., IDEA '97) may have surpassed the current professional practice, educators are still faced with fully utilizing the functional behavioral assessment proscribed in IDEA '97. Professionals in public education have responded to the legislation and research alternatives in behavior change methods with the development of new local policies to positively change the behavior of students with disabilities. The professionals responsible for influencing behavioral change in students are implementing methods under the rubric of "functional behavioral assessment." Functional behavioral assessment calls for an examination of the purpose of behavior before an intervention is assigned.

\section{The Present Study}

Functional behavioral assessment is the process of identifying events that reliably predict and maintain problem behaviors. The purpose of functional assessment information is to improve the effectiveness and efficiency of behavior support (Horner, 2000). The Miami - Dade County Public Schools, in response to change in legislation 
(i.e., IDEA '97)) and professional practice has initiated a large-scale training program in the functional behavioral assessment. With IDEA ' 97 , Congress sought to help schools (a) respond appropriately to behavior problems of students with disabilities, (b) promote the use of appropriate behavioral interventions, and (c) increase the likelihood of success and school completion for some of our most at - risk students (Hartwig \& Ruesch, 2000). The enormous implications of the IDEA' 97 legislation calls for a training effort like that in Miami - Dade County Public Schools. The legislation does not delineate the provisions for a functional assessment; rather, the law tells us when one must be performed. In view of this omission, educators are responsible for the development of a standard for conducting functional behavioral assessments.

Problem Statement

In light of the sweeping changes in educational policy, local districts now have the task of training teachers and other school personnel, implementing programs, and evaluating their efforts in functional behavioral assessment. Functional behavioral assessment calls for an examination of the purpose of behavior before intervention is assigned. The Miami - Dade County Public Schools (M - DCPS) is the fourth largest school district in the United States with 368,123 total students in 401 schools. This large number of students serves as the backdrop for an investigation into the effectiveness of educator training in the functional behavioral assessment pre - intervention process. Students with disabilities make - up a sizable proportion of students enrolled in the district. A total of 62,686 students receive services in special education programs. Students with learning disabilities make - up $34 \%$ of the total, while students with emotional handicaps make up $4.5 \%$ of the total. Students with learning students and/or 
students with emotional handicaps are a growing population of students who may benefit from the functional behavioral assessment pre - intervention process (Nelson, 1997). In response to a concern about appropriate interventions for problem behavior and in response to legislation the district has initiated a large - scale training program in functional behavioral assessment. To date no formal research has been conducted on the effectiveness of this training effort by the district.

Functional behavioral assessment should be considered within the broad framework of effective teaching and school disciplinary procedures (Conroy \& Davis, 2000). Since teachers are charged with the task of changing students' problem behavior, an investigation is necessary of the most effective and efficient manner in which to train them in behavior change technology. Teachers and administrators need in - depth training and the opportunity to use techniques that they learn, and on - going support in the use of those techniques (Johns, 1998). The legislation in IDEA '97 called for a fundamental change in the manner in which problem behavior is understood and then interventions developed. If such a change is to take place throughout America's public schools, training, continuous support, and evaluation of the training in functional behavioral assessment should be conducted. To date there is no direct inquiry into the efficacy of short - term intensive training for teachers in the functional assessment of behavior technology. An inquiry into the fourth largest school district sponsored training program will offer insight

General Purpose of the Study

The primary purpose of this study is to assess the knowledge and application ability of functional behavioral assessment in educational professionals. In addition, 
educational professionals were asked to make recommendations in relation to an intervention that results in a relatively quick and long - lasting change in problem behavior. The participant pool was selected from the school district in which some teachers participated in a district training program, while others teachers have not been trained. A secondary purpose is to determine the interventions likely to be implemented by teachers to ascertain whether they relate to the function of the original problem behavior. In short, this study examined whether training results in teachers' ability to identify function, and then base interventions on that function.

To date there is no direct inquiry into the efficacy of short-term intensive inservice training for teachers in functional behavioral assessment technology. An inquiry into a large urban district (i.e., Miami - Dade County Public Schools) sponsored training program will offer insight into the impact of functional assessment training on teacher practice.

The study has potential significance for several reasons. First, the recent shift in methodology for changing problem behavior of children with disabilities is based on a functional behavioral assessment model. An active effort should be made to determine teachers' working knowledge of the process and their ability to implement this process to change children's problem behavior in school settings. In addition, students with disabilities displaying single or multiple problem behaviors have traditionally been excluded from general education classrooms. A methodology that enables teachers to influence behavior change may promote inclusion of students with disabilities in general education classrooms and operate as a helping agent during transitions into work and community environments. 
Research Questions

Question \#1: $\quad$ Is there a difference in the ability of untrained and trained teachers to identify the function of students' problem behavior as a result of a brief training program conducted by a large urban district?

Question \#2: $\quad$ Is there a difference between untrained and trained teachers' recommendations for changing problem behavior as a result of a brief training program conducted by a large urban district?

Hypothesis \#1: $\quad$ Teachers who have been trained in the functional behavioral assessment process are more proficient in their ability to identify the function of students' problem behavior than those teachers who have not been trained.

Hypothesis \#2: $\quad$ Teachers who have been trained in the functional behavioral assessment process will recommend more function - based positive interventions than those teachers who have not been trained.

\section{Summary}

The current study is intended to examine the ability of educators to determine the function of problem behavior and make recommendations based on the perceived function of behavior. Federal legislation is the most influential factor alternating the manner in which educators respond to problem behavior. Students with disabilities who exhibit problem behavior that warrants suspension from school for an excess of ten days, must have a functional behavioral assessment (FBA) performed before an intervention is developed. It is critical that the field of education has insight into training efforts aimed at teaching educators how to perform an FBA. 


\section{CHAPTER II}

\section{LITERATURE REVIEW}

The proposed evaluation of a public school training initiative will contribute to our professional knowledge about the current state of teacher training in new functional behavioral assessment methodology. Previous studies in the area of functional assessment have been conducted on the development and maintenance of the technology itself. In contrast, this study will contribute to our understanding of educator abilities' to identify the function of problem behavior and make recommendations to promote change in problem behavior. An evaluation designed to assess the knowledge and application abilities of teachers has not been conducted to date.

Federal and state laws shape the field of special education. Beginning with the Education for All Handicapped Children Act (1975) to the reauthorization of the Individuals with Disabilities Education Act (1997), educational professionals and community agencies have been and will continue to be influenced by the standards set forth in legislation. Each piece of legislation is coupled with regulations that delineate the service delivery guidelines for individuals with disabilities. The reauthorization of IDEA 1997 brought a host of changes that directly effect service delivery for individuals with disabilities. One significant change from previous legislation is the manner in which challenging behavior is assessed and treated.

Additions to IDEA 1997 are underscored by two major influences. The first generally accepted notion among special educators is that exclusionary discipline is ineffective as a means of promoting positive behavior change (Nelson, 1997). In addition, there is a growing concern that the degree of violence is more severe and is being 
committed by younger and younger students than in the past (Bender \& McLaughlin, 1997). There is a great concern that violence perpetuated by younger children points to a greater concern that school is not "safe" environments for children to learn and develop. The 1997 changes to IDEA mandate that schools take a more proactive and positive approach to the disciplining of students with disabilities (Zurkowski et al., 1998). This approach requires the use of functional behavioral assessment (FBA). An FBA can be defined as a comprehensive examination of student behavior and the conditions that surround that attempts to discover the purposes, goals, or function of the behavior based on observations, interventions, review of records, and assessment of environmental expectations (Kauffman, 1997).

Administrators and teachers alike are charged with identifying challenging behavior and further, developing an intervention to eliminate and replace the challenging behavior. According to Dunlap and Koegel (as quoted in Drasgow et al., 1999) addressing a student's problem behavior includes two key factors. The first is conducting a functional behavioral assessment of the student's problem behaviors. The second is developing a behavior intervention plan (BIP) that includes positive behavior support strategies that are nonaversive and do not rely on coercion or punishment for behavior change.

Federal legislation is designed to provide the backdrop by which interventions are developed for students with disabilities. IDEA '97 provides the groundwork for precise and systematic methods by which to identify challenging behavior. The grand scheme for managing challenging behavior is present while the details of the plan are not necessarily included (Yell et al., 2001). The philosophical foundation provided by IDEA '97 does 
direct educational professionals to define challenging behavior clearly so that they can be observed and measured (Murdick \& Gartin, 1999). This shift from "topographical intervention" based on the look of challenging behavior without regard for the purpose of behavior is the emphasis of the IDEA '97 regulations.

\section{A Movement Toward a Technology of Behavior}

Educators are often bombarded with several instructional and curricular initiatives on a yearly basis. Each of these initiatives is hailed as the cure all for those ills plaguing classrooms, schools, or even entire districts. Many of the accepted educational practices are often scrutinized heavily for their "fit" into classrooms or entire schools. While individuality clearly exists on all links of the educational chain, many educators continue to look for "one size fits all" interventions. This notion is applicable to instruction, curriculum, and even behavior support. In the midst of great cultural and linguistic diversity in public schools, there also exists a great behavioral diversity that requires individualized behavior support. In the past, educators did not conceptualize challenging behavior as having a purpose. Focusing on the form of the behavior may not reveal its function, and similar forms (e.g., yelling and hitting) may serve different purposes for different students (Iwata et al., 1982).

An FBA is the first, and most critical, step toward developing a BIP because it guides the selection of an intervention strategy that is related (a) to the purpose of the problem and (b) to the specific circumstances and context of each particular student (Drasgow et al., 1999). Conducting an FBA and then developing a BIP is the standard of practice set forth in IDEA ‘97. 
Educators have traditionally viewed academic instruction as distinctly separate from social skill instruction (Colvin, 1993). This distinction may have been more harmful than beneficial as educators viewed challenging behavior as social deviance rather than a deficit in social skills. The greatest tool available to educators is instruction. A wide variety of instructional technologies is available to assist students develop special skills. According to Brophy as quoted in (Englert, 1984) effective teachers often use semiformal lessons to actively instruct students in their rules and routines, just as other academic behaviors are taught. Empirically - validated instruction is well documented for students with disabilities (Keel et al., 1999). One of the defining characteristics of effective instruction is a clear relationship between teacher instruction and student outcomes. According to Cronbach's context - approach (as quoted in Reid \& Maag, 1998) treatment or intervention options should be analyzed from the perspective of outcomes. The interaction between the environment and behavior provides meaning and allows for educators to observe and identify a function of behavior.

The revised emphasis of behavioral intervention is not focused on managing or controlling individuals, but instead on redesigning the environment and on building new skills that make the problem behavior irrelevant, inefficient, and ineffective in that environment (Horner \& Carr, 1997 as quoted in Reid \& Maag, 1998). The FBA process involves systematic data collection methods (i.e., interview and descriptive observation). Educators now have access to a system or technology in which to assess the function of challenging behavior. A critical step in the FBA process is the identification of a relationship between environmental events and behavior. Data collection methods provide educators with the information necessary to develop a hypothesis statement. 
Hypotheses are generated on the basis of available information; assessment methods are implemented to determine probable relations between a child's behavior and environmental variables (Reid \& Maag, 1998).

According to Johns and Carr (1995) as quoted in Murdick and Gartin (1999), effective teachers utilize specific components in effective programs for individuals with disabilities. These components include the ability to (a) analyze behavior and the situations(s) in which it occurs; (b) identify numerous possible strategies to use with the behavior; (c) provide continuous monitoring of the student's program; and (d) revise the program as needed to assure success. FBA is one component of a behavioral technology from which educators are now required to utilize for students who exhibit challenging behavior.

Challenging behavior can inhibit students with disabilities from having full access to the general education curriculum. Problem behavior is the single most common reason why students with disabilities are removed from general school, work, and home settings (Anderson et al., 1993). The overwhelming response to challenging behavior consists of negative consequences from their teachers. Unfortunately, evidence suggests that current school discipline practices exacerbate and contribute to children and youth's patterns of challenging behavior (Lewis \& Sugai, 1999). Mayer (1995) as quoted in Lewis and Sugai (1999) state that high rates of antisocial behavior in schools are associated with punitive disciplinary strategies, lack of clarity about rules, expectations, and consequences, lack of staff support, and failure to consider and accommodate individual differences.

The development of a behavioral technology is clearly apparent in the emerging literature on positive behavior support (PBS). PBS is an applied science that uses 
educational methods to expand an individual's behavior repertoire and a systems change method to redesign an individual's living environment to, first, enhance the individual's quality of life and second, to minimize his or her problem behavior (Carr et al., 2002). The PBS service delivery model assumes there are system problems influencing individuals as opposed to holding notions about problems residing in individuals. Assessment, intervention, and evaluation have all been heavily influenced by the perceived worth of punitive measures. PBS calls into questions the validity of punitive measures for use with individuals and/or in a school wide system.

PBS emerged from three major sources: (a) applied behavior analysis, (b) the normalization/ inclusion movement, and (c) person - centered planning (Carr et al., 2002). The extensive work conducted in Applied Behavior Analysis (ABA) contributes the systematic methods for assessment and intervention for application in natural settings like schools. The normalization/inclusion movement is a highly influential philosophical construct calling for access to natural environments for individuals with disabilities including schools. Finally, person - centered planning assists practitioners in deciding what is worth changing by focusing on a comprehensive planning process for individuals before intervention (Carr, 1994).

Behavior technology is steadily assisting educators to better assess and develop interventions that "fit" individual need and provide support to those support individuals with disabilities. PBS turns the traditional response mode from reactive to proactive. The major philosophical thrust of PBS is prevention of challenging behavior before it is perceived to be challenging. This proactive approach is the most appropriate time for direct instruction in alternative skills. The strength of PBS and the continued use of 
procedures like FBA contribute to the acquisition and maintenance of pro - social and academic skills. These skills will enable individuals with disabilities to have access to natural environments (e.g., general education classrooms) that have been cut off in the past.

Functional Assessment

Purpose

A basic purpose of functional assessment is to identify variables that improve the effectiveness and efficiency of a clinical intervention (Day, et al. 1994). Educators are challenged with translating the best practices (i.e., empirically - validated strategies) into school - based interventions that bring about a lasting change to challenging behavior. According to Carnine (1997), a goal of research in the social and behavioral sciences is the improvement of practice. In the past, educators were inundated with information about children and their behavioral deficits. This information was not considered in the context of function, but rather focused on a topographical description of challenging behavior. Thereby, interventions were not individualized or considered for their "contextual fit." Interventions were blindly applied to children regardless of behavioral function. Mace (1994) makes two salient points in relation to the importance of determining function before intervention. First, the field's methodological approach soon drifted from analyzing function to focusing on the topography of behavior (via behavior modification). Second, behavior modification places emphasis on "altering existing repertories and establishing new ones by superimposing reinforcement contingencies, punishment contingencies, or both, onto the current environmental contingencies or 
unknown processes that maintain aberrant behavior" (as quoted in Fowler \& Schnacker, 1994).

\section{Determining the Function of Behavior}

Carr and Durand (1985) proposed that functional analysis provides the basis for building identification and assessment methods. Essentially, functional analysis and/or functional assessment are pre - treatment processes. The purpose of functional assessment is to improve the effectiveness and efficiency of behavioral treatment (Horner, 1994). The movement away from selection and implementation of behavioral interventions without consideration of "motivation" began with Carr (1977). This seminal study detailed five major hypotheses concerning the motivation for self - injurious behavior. This work gave rise to the research conducted later by Iwata et al. (1982). The Iwata et al. (1982) study provided an unprecedented experimental methodology to identify the environmental determinants of self - injurious behavior; moreover, it was sufficiently comprehensive to permit analyses across a wide variety of settings, behaviors, and subjects. The emerging functional assessment technology introduced a "new line of thinking" for individuals who provide behavioral services. Two questions put forth by Mace (1994) characterize this alternative thinking: "Why does a given behavior problem occur?" and, "Why does the behavior persist in the face of treatment procedures that should be effective?"

The ineffectiveness and even failures of behavioral treatments used for individuals displaying challenging behavior influenced researchers to continue the development of functional assessment technology. These failures prompted investigators to return to what is arguably the central idea of applied behavior analysis, namely, that 
intervention efforts should begin with a thorough functional analysis and that hypotheses derived from such an analysis should form the basis for choosing and designing treatments (Carr, 1994). In a meta - analysis study conducted by Didden et al. (1991), 482 empirical studies on treatment of behavior problems were reviewed. Findings indicated that conducting a functional analysis made a significant contribution to treatment effectiveness. In a similar meta - analysis study conducted by Scotti et al. (1991) functional analysis was described as a necessity for adequate treatment design. In light of the functional assessment methodology, professionals are asked to not only consider pre - treatment assessment, but also the quality of life for persons displaying problem behavior. This sentiment has emerged along with recognition that it is unfair and unethical simply to promote compliance; educators must also help people to learn the skills needed to succeed in real world settings (Scotti et al.,1991). As the focus shifts from controlled, often artificial research contexts to the practical demands of school and home, a reexamination of functional assessment methodology has taken place (Horner, 1994). There is now a broad consideration for a number of factors that were not considered in the past. Individuals displaying challenging behavior deserve interventions that can be implemented within their home and/or school environment. Often times, interventions were intrusive and did not consider a "contextual fit" for the environments in which implementation took place. This lead to highly intrusive interventions that were not implemented consistently or not implemented at all. The current emphasis on positive life enhancing interventions underscores the overall movement toward a positive behavioral technology. Comprehensive interventions based on functional assessment are 
intended to reduce or eliminate challenging behavior, and to teach appropriate social skill so that individuals can directly benefit from inclusion in the community at large.

Teachers are specifically charged with assisting students who experience academic and/or behavior problems. Classrooms are generally conceived as the first, and in general, the most appropriate environment for general instruction and if necessary behavioral intervention to take place. The classroom is absolutely essential to students and teachers for the "business of school:" learning. It is incumbent upon teachers to create and maintain a classroom environment in which students not only learn, but also detect behavioral problems and implement procedures to correct those problems. This is no easy task if one or more of the students in the class exhibit challenging behavior. Academic instruction may come to a halt several times during the day or may stop altogether as teachers try to "manage" the challenging behavior. In Gettinger (1988), Duke (1979) broadly defined classroom management as the "provisions and procedures necessary to establish and maintain an environment in which instruction and learning can occur."

In an attempt to "manage the classroom," teachers have generally responded to problem behavior in the same manner. Teachers embrace punishment because it is easy to administer, works for students with only minimally challenging behaviors, and has been part of the Judeo - Christian history that dominates much of our society (Maag, 2001). While teachers have made punishment the intervention of first choice, the research base on alternatives to punishment continues to grow. Successful classroom management involves not merely responding effectively when problems occur, but also preventing 
problems from occurring by creating environments that encourage learning and appropriate behavior (Gettinger, 1988).

The predominant, "one intervention fits all" is applied to students' challenging behavior, while teachers do not use the same reasoning in relation to students' academic behavior. In an instructional (Colvin et al., 1993) or educative (Rietz, 1994) approach to addressing behavior management, educators view students' participation and interaction behaviors in a way that is similar to their view of students' academic behaviors (as quoted in Carpenter \& McKee - Higgins, 1996). The emphasis placed on the selection of curriculum and instructional implementation for children with and without disabilities sends a clear message as to the importance of teaching academic skills. In contrast, educators and parents both discuss behavior problems as potential barriers to the learning process. The same time and effort is not placed into the development of "behavioral skills." The development of behavioral skills is left to chance without the benefit of formal instruction (Carnine, 1997). The school should be viewed as an appropriate environment for instruction in a wide range of academic and social topics.

According to Fantuzzo and Atkins (1992) there are several factors that make schools an ideal setting for identifying and treating children with academic and adjustment difficulties. First, teachers have the most extensive adult contact with children outside of the home. Second, the availability of a large group of peers provides teachers with age and gender appropriate norms to help them identify adaptive and maladaptive behavior. Third, the school environment requires children to perform a wide variety of tasks requiring physical, cognitive, emotional, and social competencies. Schools provide an environment for educators to effectively assess, develop, implement, and evaluate 
effective behavioral programming. In view of the importance placed on classroom - level intervention (developed, implemented, and evaluated by the classroom teacher), it is essential that teachers make use of strategies that emphasize the development of skills. Punishment may influence students to temporarily stop engaging in behavior. The shortfall of punishment is the lack of any skill development for use in future situations.

\section{Positive Behavioral Interventions}

A movement toward nonaversive, positive interventions for students who exhibit challenging behavior has promise to assist teachers to influence behavior change without punishment (O’Brien \& Repp, 1990). Moral arguments challenge the appropriateness of any intervention that causes pain, physical or emotional distress. Interventions are also challenged if it is objectionable for same - age peers without disabilities given that an individual's personal dignity and possible rights (i.e., lack of informed consent by the person receiving treatment) may be violated in the process (Bambara et al., 1994). Educators have access to positive interventions that are intended to promote valuable skills for use in schools and the community. Positive approaches emphasize teaching alternative skills that produce the same outcomes as the problem behavior and that will prevent problem behaviors from occurring in the future (Bambara et al., 1994).

Most nonaversive or positive treatments emphasize the role of environmental events that occasion or consequate problem behavior (Munk \& Repp, 1994). Teachers use a variety of techniques to maintain an environment of learning in classrooms. When teachers take excessive time to respond to inappropriate student behavior, valuable instructional momentum and time may be lost (Carpenter \& McKee - Higgins, 1996). Managing the classroom includes a number of factors. In addition to students, teachers 
must manage materials, lesson development, lesson implementation, and evaluation of the lesson. Teachers dedicate a great deal of time to environmental management for the purpose of academic instruction. Punishment and other aversive procedures are not in line with the normal work patterns for teachers. These procedures require a complete move away from instruction. Nonaversive procedures are attractive because they can be relatively nonintrusive (i.e., they manipulate conditions already in the environment rather than add new ones). They are also attractive because they seem to be successful (Munk \& Repp, 1994).

Proactive behavior management programs are described as an effective means to respond to diverse behavioral characteristics among all students, both with and without disabilities (Carpenter \& McKee - Higgins, 1996). Educators who make proactive strategies a part of their instructional repertoire can promote and maintain positive behavior changes (Alber \& Heward, 1996; Buggey, 1999; Lewis, et al. 1998; Weigle, 1997). The use of positive measures to promote behavior change will facilitate the use of a readily available resource, instruction. The functional assessment technology is not simply to identify the function of a behavior or the eligibility of a student for services. The information is also used to develop comprehensive instructional plans that have a greater probability of success (i.e., to teach more appropriate skills and to decrease problem behavior) (Davis, 1998).

The current emphasis on positive interventions allows educators to facilitate student success as opposed to reacting to student failure (Scott et al., 2000). Without the use of functional assessment, educators selected interventions based on their convenience or familiarity as opposed to tailoring interventions to teach and reinforce desired 
behaviors that serve the same function (access reinforcers/avoid aversives) as the undesired behavior (Scott et al., 2000). Interventions based on positive approaches have influenced a shift for teachers away from highly intrusive methods to those methods intended to promote behavior change and the acquisition of skill.

The "positive approaches movement" is grounded in moral and philosophical arguments for interventions that respect the dignity of individuals and promote lifeenhancing skills. Educators often label students formally or informally as an attempt to identify those that may or may not cause trouble. Traditional student grouping methods call for students with and without disabilities to be segregated. Those students with disabilities who are included in general education are often quickly removed from the general classroom should they exhibit challenging behavior. One challenge for special and general education teachers is to assist each other to include students exhibiting challenging behavior in a general education classroom. In the midst of the positive approaches movement many traditional responses to challenging behavior have been called into question, including exclusion from typical, neighborhood schools. The emerging functional assessment technology is one vehicle for facilitating the inclusion of students who have traditionally been removed or excluded from the general education environment.

Critical decisions regarding the placement of a student in an educational environment should be made only after consideration of specific academic and social supports necessary for student success in the inclusive setting (Sasso et al., 1998). Functional assessment methods can be applied successfully to managing disruptive behaviors that threaten a child's continued placement in an inclusive classroom. In this 
respect, functional assessment offers a technology that can support and facilitate the inclusion process (Umbriet, 1995). The goal of treatment strategies has become twofold, incorporating decreases in aberrant behavior and increases in positive behavior (Matson et al., 1996). After determining the function of behavior, treatment decisions can be more accurately addressed thereby increasing the likelihood of more positive outcomes for both teachers and students (Watson et al., 1999). Students who respond to positive nonintrusive methods may have more opportunities available to them in the general education environment. Educators who have knowledge and skill of positive methods may also be more welcoming to the inclusion of students with learning and/or behavior problems.

\section{Functional Assessment in Schools}

As researchers work to develop the functional assessment technology a number of implementation issues remain in schools. Support mechanisms for students who exhibit challenging behavior benefit from investigators who focus on all aspects of the functional assessment process (i.e., data collection, hypothesis development, intervention, and evaluation). Vollmer et al. (1995) conducted a study to investigate methods to reduce the overall observation time for data collection and increase the likelihood of identifying function. A key outcome from this study is that a comprehensive functional analysis can be conducted in a shorter time period without comprising the integrity of the process. In 1997 Hall and Belifore analyzed the possible function of aggressive/destructive behavior by linking descriptive and experimental analyses. One implication of the research was that functional analysis methodology could be used when developing an intervention is 
easily accessible to teachers, and school staff could use the intervention after the study had concluded.

A large portion of functional assessment research has been conducted in schools. Functional assessment methods have been implemented in a number of situations involving various educational personnel (e.g., teachers, school psychologists, and para professionals). While the literature base is growing, there is still concern about the ability of classroom based teachers to conduct the necessary components of a functional assessment (Vaughn \& Horner, 1997). One reason that research knowledge is used so rarely is the fact that researchers and practitioners have limited opportunities to communicate and work together to solve instructional problems (Greenwood \& Abbott, 2001). Investigating and implementing a comprehensive pre - intervention process such as functional assessment is often viewed as the responsibility of an expert. This expert status is usually assigned to professionals who work outside of the classroom. The dilemma for educators is the struggle between the responsibilities of the classroom-based teacher and those professionals who work outside of the classroom. The question remains, "Who is ultimately responsible for developing and implementing comprehensive behavior support plans?" In spite of the answer one may provide to the previous question, the classroom - based teacher is seen as the primary individual responsible for managing behavior problems. This responsibility calls for training and access too empirically validated practices in order to support individuals and promote positive behavior change.

The challenge that arises for all educators is the difficulty with which empirically - validated practices can be included within current practices. Typically, inservice training is the primary means by which people (i.e., teachers) in the field stay abreast of 
current developments in theory and practice. Effective inservice training approaches, capable of reaching a wide audience, are essential (Anderson et al.,1993). The gap between the current research base and teacher practice requires an effort to provide teachers with instruction in function - based methods to bridge that gap. To locate gaps in content knowledge it may be beneficial to begin by surveying what assessment and behavioral management techniques inservice educators currently employ (Shellady \& Sticher, 1999). In response to training gaps, comprehensive training can be developed and implemented. Comprehensive training must be delivered in a manner that promotes application across a variety of conditions over long periods of time (i.e., generalization and maintenance) (Anderson et al., 1993). Making Functional Assessment Work

Inservice training is a necessary component of education since educators are constantly faced with meeting students' diverse learning and behavioral needs. Few educators have had sufficient training in individualized instruction, behavior management; teaching social skills, group instructional strategies, consultation, collaboration, and team teaching to meet the day - to - day needs of challenging students (Hendrickson et al., 1999). In addition to exposure to the material teachers need "an opportunity to infuse new learning in daily practice" (Gable et al., 1992 as quoted in Hendrickson et al., 1999). The need for inservice training does not speak to the manner in which the training will take place.

"The conventional view of staff development as a transferable package of knowledge to be distributed to teachers in bite - sized pieces needs radical rethinking" (Lieberman, 1995, p. $591-592$ as quoted in Shellady \& Stichter, 1999). The key to 
effective implementation of a functional behavioral assessment and intervention model will depend upon trainers' ability to create a comprehensive and interactive training program, encourage school - wide implementation, and facilitate successful outcomes via ongoing support (Scott \& Nelson, 1999). The content and delivery of functional behavioral assessment must bring together the most effective training techniques to facilitate its use in school settings.

Functional behavioral assessment will require trainers' to assist teachers build competence in the technology. To build competence in the use of FBA, schools must (a) establish a philosophical foundation for all students to remain in school, (b) create support within school systems for implementing FBA, and (c) produce professional within the school that have expertise in FBA (Conroy et al., 1999). The content and delivery of inservice training are important for influencing teachers to understand and utilize FBA methods. In many instances classrooms are staffed with one teacher. One of the landmarks of special education is the low teacher to student ratio. Teachers are the focus for training in FBA methods, but this does not imply that teachers will work alone to implement behavioral support. To realize the potential of FBA's, student - centered teams need to understand four critical points. The first step is to ensure that the FBA process is understood by all responsible personal. Second, team members need to be familiar with the array of tools and processes that are available. Third, team members need to know that these tools and processes occur along a continuum of resource intensity and empirical rigor. Fourth, team members should be able to develop a process for selecting relevant tools and processes at given points along this continuum (Knoster, 2000). 
As FBA training emerges in school districts, questions still remain as to the manner in which the content should be translated into a training program. The research base for FBA is strong, but this strength does not directly translate into methods readily adopted by teachers. Strengthening the link between research and practice appears to require consideration of two related problems: (a) getting researchers to do better research and (b) getting the constituents who write educational policy and choose specific practices to make better choices (Kauffman, 1996). Gable (1995, p. 39) concluded that "our understanding of the boundaries of functional assessment in terms of who can and cannot feasibly apply it, in relation to what target behaviors and under what conditions, remains limited" (as quoted in Gable, 1999).

Despite the many issues facing educators who access FBA methods the general goals of the special and general education environment remain the same. Educational environments are effective, in part, when children are learning valued skills, prosocial behaviors are encouraged and displayed, and violent or disruptive behavior is at a minimum (Sugai et al., 1999). It is essential that educators engage in the necessary staff development activities (i.e., inservice training) to utilize those methods which increase efficiency and effectiveness of behavioral interventions. Despite the possible aversion to new techniques (e.g., FBA) educators have good reason to adopt empirically - validated strategies. Professional judgement alone can not supplant monitoring the implementation of an intervention or measuring its effect on the occurrence of behavior (Gable, 1999). The ultimate goal for an educator is to build an FBA technology that meets the full range of situations faced in schools, homes, and communities (Sugai et al., 1999). 
A third critical issue in relation to training in FBA methods is the evaluation of teachers' ability to determine function and make recommendations based on function. There are few data to inform the field that school - based personnel can determine behavioral function reliably (Gresham et al. 1999). Researchers have spent a great deal of time developing functional assessment methods (O'Neil, et al. 1997). The work completed up to this point has provided educators with the foundation necessary to translate the clinical research of functional analyses to the applied research that is functional assessment. The movement from clinical to applied is necessary for educators to have the technology available to assist in the development and implementation of interventions. The missing link from the current body of literature is an investigation into the events that take place after function is determined.

\section{Evaluating Functional Assessment}

Currently the literature does not include an investigation into educators' ability to determine function, develop hypothesis statements, and make recommendations for interventions. It is important for school-based personnel and researchers to better understand the current state of educators' abilities to use FBA methods. The legislative call for FBA methods only provides the impetus for use of the technology. The use of the technology does account for competency and efficiency of its use. If educators have access to training but do not have a sense of their own ability to use the technology, then a gap exists between an empirically - validated practice and its implementation.

The development and implementation of new practice is a slow process at best. This process is subject to a number of influences. Training in FBA methods have been overshadowed by non - standardized competencies and inservice training procedures 
(Hendrickson et al.,1999). School districts, individual school sites, and special education researchers lack information detailing educators' abilities to determine function. In view of legislation and the research base validating function - based methods, it is essential to begin investigating educators' abilities to determine function.

Content, implementation, and evaluation of FBA training efforts are all critical to the development of educators' competence in FBA methods. In addition to these issues it is also necessary to consider the response from district and school - based personnel to take on the training challenge. The use of FBA methods will have ramifications in several areas of school operations. First, current responses to challenging behavior will be altered. Second, educators will use an empirically - validated strategy (i.e., FBA) to guide the choice and implementation of behavioral interventions. Third, students who have been traditionally excluded from general education settings will ultimately be included in these settings due to innovative, effective behavioral support methods. Finally, educators will implement behavioral interventions with a vastly different intent. The current positive behavioral support service delivery model (Carr et al., 2002) calls for consideration of behavior change across time and settings.

Educators now have the ability to use information gained from an FBA to reduce future occurrences of challenging behavior and promote replacement of the behavior that satisfies the same need for the student but is more socially acceptable or appropriate (Gable et al., 1999). If students are able to benefit from interventions specifically designed to teach socially acceptable skills, more inclusive opportunities are possible. All too often, students are placed in mainstream (i.e., general education) settings based on criteria not directly related to their individual strengths and needs. It is known that 
aberrant behavior and poor or absent social skills are the primary inhibitors to successful inclusion of students with special needs in general education settings (Peck et al., 1998). In the midst of attempts to implement IDEA legislation, educators face a number of barriers that impede full utilization of FBA methods.

As functional behavioral assessment moves from clinic to classroom, researchers and practitioners must work together to develop measurement systems and intervention procedures that are responsive to the complex demands of treatment in applied settings (Gable et al., 1999). In response to the complexity of FBA methods, a comprehensive inservice training component is needed to develop competence among school personnel who may have varying levels of knowledge and skills in FBA (Conroy et al., 2000). School - based personnel will need access to comprehensive frequent training sessions in order to assist those individuals with varying levels of skills and opportunities to utilize the training. According to Quinn (2000), individuals charged with conducting a FBA will need intensive training in direct and indirect data collection procedures, and choosing and implementing appropriate interventions. The ability of school - based personnel to actively engage in training efforts will largely dictate the successful implementation of FBA methodology.

\section{Summary}

Special education is largely driven by legislation (e.g., IDEA '97). The diversity of students and the need to respond to vastly different learning and behavior needs provides the backdrop for movement away from traditional responses to challenging behavior (e.g., punishment, exclusion) toward a positive behavioral support. Proactive, nonaversive or positive interventions are based on a fundamental philosophical belief in 
quality of life enhancement as well as behavior change. The reduction or elimination of one behavior without the systematic development of an appropriate socially relevant replacement behavior is simply insufficient for students with disabilities. The introduction of comprehensive behavioral support plans based on conducting functional behavioral assessment is one of the greatest challenges placed on educators in response to legislation. While the challenge is great, the rewards are greater. A pre - intervention procedure that is capable of providing information to educators that enhances the intervention is a sorely needed procedure. FBA methods are deigned to enhance interventions that will allow educators to influence positive, long lasting behavior change.

The many barriers presently impeding implementation and evaluation of FBA methods require researchers to investigate a number of factors. One of the most critical of these is the ability of educators to determine the function of challenging behavior. Without specific data on educators' ability to determine function, students are faced with the same dilemma as in the past: insufficient interventions that teach socially appropriate behavior. Students who do not have the skill and/or motivation to engage in socially acceptable behavior may not have access to general education settings. This denied access might lead to a significant decrease in broader educational opportunities. This is counter to the progressive inclusive movement. By evaluating educators' ability to determine function, conclusions can be drawn in relation to the necessary steps to be taken for further implementation and use of empirically - validated FBA methods intended to benefit students with disabilities. 
It is critical for educators to adhere to federal legislation, but it is also critical that educators access empirically sound technology for the benefit of students. Functional analysis has evolved over the past fifteen years from a clinical application in institutions to change self - injurious behavior to an assessment technology that is applied in schools, homes, and the community. In light of these developments FBA can enhance the integrity of interventions for a greater chance of successful behavior change in public schools. 


\section{CHAPTER III}

\section{METHOD}

This research was conducted in the fourth largest district in the southeastern United States, the Miami - Dade County Public Schools (M - DCPS). For the last four years, $M-D C P S$ has made an effort to train the vast majority of professionals working with students with disabilities. The training effort was directed at those individuals based in schools, those who work in more than one school, and those who work in the main district or region offices. Training was conducted on a continuous basis over the previous three school years and continues to the present. Permission to conduct this study was obtained from the Office of Evaluation and Research of the M-DCPS (see appendix C). Permission was also obtained from the Florida International University Institutional Review Board (see appendix C).

The M-DCPS conducted four to six training sessions during each of the three previous schools years. The training sessions were held in the northern and southern parts of Miami - Dade County. The facilities chosen for the training session were equipped to accommodate between 50 and 150 people at one time. The training sessions were not held on any the M - DCPS school campuses. Local hotels and conference centers severed as the training facilities for each of the sessions. Since the district is divided among racial and ethnic groups (see Table 1), the present study may offer additional insight into the many questions associated with "diverse" districts serving students with disabilities. 
Table 1

Student Demographics in $M-D C P S$

\begin{tabular}{llllllll}
\hline $\begin{array}{l}\text { Total } \\
\text { number } \\
\text { of } \\
\text { students } \\
\text { in }\end{array}$ & $\begin{array}{l}\text { Total } \\
\text { minority }\end{array}$ & $\begin{array}{l}\text { White } \\
(\%)\end{array}$ & $\begin{array}{l}\text { Black } \\
(\%)\end{array}$ & $\begin{array}{l}\text { Asian/Pacific } \\
\text { Islander } \\
(\%)\end{array}$ & $\begin{array}{l}\text { American } \\
\text { Indian/ } \\
\text { Alaskan } \\
\text { native } \\
(\%)\end{array}$ & $\begin{array}{l}\text { Multi } \\
\text {-racial } \\
(\%)\end{array}$ & $\begin{array}{l}\text { Hispanic } \\
\text { origin } \\
(\%)\end{array}$ \\
\hline 368,123 & 326,906 & 11.20 & 30.97 & 1.22 & 0.08 & 0.67 & 55.87 \\
\hline
\end{tabular}

Participants

A group of educational professionals were recruited from the listing of schools in the M - DCPS with twelve or more teachers certified in one or more areas of special education. The large scale training effort conducted by the M - DCPS in Functional Behavioral Assessment included an array of educational professionals serving students with disabilities in various capacities. The district trained many professionals during this staff development effort (i.e., teachers, school counselors, school psychologist, and administrators). While the curricular content of the training program remained the same, the instructional delivery varied according to the group attending the particular session. The training program was tailored for various professionals depending on the time allotted and the ultimate function of the content for a particular professional. The administrators received a training program which included an emphasis on the "letter of the law" contained in IDEA '97, while school psychologists, counselors, and teachers received the letter and the sprit of the law contained in IDEA '97. At each session, teachers, school counselors, and school psychologists also received direct instruction in the process necessary for conducting a functional assessment. 
Classroom teachers and the school counselors are responsible for the direct application of the content taught in the Functional Behavior Assessment training package. Classroom teachers and school counselors are also responsible for determining and then implementing the interventions necessary to promote change in problem behavior. For these reasons, teachers and school counselors were selected for participation in this study. Teachers and school counselors were recruited for the experimental group based on the list of those individuals who have participated in the Functional Behavior Assessment training over the last four school terms (i.e., $1998-1999,1999-2000,2000-2001$, and 2001 -2002). The sample of teachers refers to a professional who holds certification in an area of special education (e.g., varying exceptionalities). Other individuals who hold certification in an area outside of special education (e.g. social studies) but assignment is in a special education classroom, or a teacher seeking certification in an area of special education. The participants were asked to answer five demographic questions. First, participants were asked to identify their certification status (i.e., certified versus not certified). Second, participants were asked to identify their professional assignment (i.e., students in the classroom). Third, participants were asked to identify the primary grade taught. Fourth, participants were asked to indicate their teaching experience as measured by a range (e.g., $0-3)$. Finally, participants were asked to indicate any special behavioral training they may have received (e.g., university courses or training in Applied Behavior Analysis).

This study did not include any Miami - Dade County School employee with the title of para - professional, para - teacher, classroom assistant, or instructional aide. While these individuals are responsible for the implementation of the intervention based 
on the functional assessment, it is not the intent of this study to assess the knowledge or application ability of this group.

The sample of school counselors refers to those individuals who work in a school and assist students with disabilities as defined in their duties. The sample of school counselors was restricted to those individuals who (a) hold the title of school counselor, and (b) hold certification in guidance counseling.

Participants for this study were drawn from the pool of individuals who obtained training from 1998 to the present. The approximate number of individuals who obtained trained in FBA is 2000 . Schools with large populations of students with disabilities served as the selection pool for the study. Trained and untrained educators who worked in these schools for participated in the study. Teachers and school counselors were encouraged to participate in this evaluation effort for the potential of information available to the district.

The control group for this study was defined similarly to the experimental group. The teachers and the school counselors in the control group only differed from the experimental group in that these individuals did not have any training in the MiamiDCPS on Functional Behavior Assessment. These participants were encouraged to participate in the evaluation effort to offer the district information for possible improvement in the training process and based on a direct appeal from select exceptional student education administrators.

\section{Design of Study}

The research used a post - test only experimental design. The evaluation instrument was a combination of closed - end questions and one open - ended question 
(this question is asked on six different occasions in the instrument). The closed - ended questions were designed to evaluate the participants' knowledge of function of problem behavior, and the application of identifying the function of problem behavior. The one open - ended question was designed to evaluate the participants' recommendations for interventions for promoting change of problem behavior. Each sample of participants was asked to complete the evaluation instrument. The open - ended questions were scored later by the primary investigator using an original rubric. The rubric yielded categorical data for analysis.

\section{Data Analysis}

The data analysis was conducted using the computer package SPSS Windows. A host of comparisons were made using one main statistical procedure. The factorial Analysis of Variance (ANOVA) was used to analyze the data. The evaluation instrument was divided into three sections. The first section of the evaluation instrument asked participants for demographic information. In this section descriptive statistical analysis was used to detail the frequency of various sample distributions (e.g., grade level assignment). The first section was closely analyzed for data indicating the training status of each participant. This information allowed for the formation of the "trained" and "untrained" groups. In section two, participants were asked to apply their knowledge of identifying the function of problem behavior and then make a recommendation about an intervention to promote change of the problem behavior. In section three of the evaluation instrument, participants were assessed on their general knowledge of basic principles underlining the functional assessment of problem behavior. 
Each section of the evaluation instrument was analyzed separately. In section one; the demographic information was analyzed for the distributions of the various characteristics of the participants. This data yielded information indicating the differences among groups as well as the similarities amongst the groups.

In section two of the instrument the open - ended question asked for a recommendation. These recommendations for a behavior intervention were analyzed using an original rubric (see appendix B). Participants were asked to write - in a response detailing their personal recommendation for a "relatively quick, long - lasting" intervention to change the problem behavior described in the accompanying scenario. The rubric delineated the "standard criteria" for a recommendation. By employing the rubric in the data analysis the researcher was able to evaluate the ability of both groups (i.e., experimental and control) to recommend a relatively quick, long - lasting intervention for the hypothetical student. The score generated from the rubric allowed for an analysis to determine if a significant difference exists between the experimental and control groups in regards to the two groups' ability to reach criterion for a recommendation to change problem behavior.

In section three, the data was analyzed using a factorial ANOVA to compare the mean scores based on closed - ended questions obtained by the experimental (i.e., trained teachers) and control groups (i.e., untrained teachers). This set of multiple - choice questions were designed to assess the knowledge level of participants in relation to general areas of behavioral assessment. The data was analyzed for a significant difference between the experimental and control groups' ability to accurately answer questions in relation to general areas of knowledge about functional behavioral assessment. The 
questions were based on the content presented in the official training manual utilized for the training program in the district.

Instrumentation

Description of the Instrument

An original evaluation, the Survey of Intervention Practices Used for Students Exhibiting Challenging Behavior was used to assess participants' knowledge of function of problem behavior, ability to apply knowledge of identifying function of problem behavior, and ideas about intervention to change problem behavior.

Knowledge of function items. The first section of the evaluation instrument asked participants to provide demographic information. This information allowed the researcher to define the experimental and control groups. In addition, the demographic information allowed for indication of elapsed time from the original training to this evaluation, previous training in behavioral methods, and certification areas.

Recommendation measurement. The evaluation instrument consisted of hypothetical scenarios describing a student who exhibits problem behavior. The participants were asked to read the scenarios, and then identify the function of problem behavior. Further, the participants were asked to recommend a relatively quick and long lasting intervention to promote behavioral change for the student. This recommendation served as the conduit into the current thinking into the about interventions. The instrument consisted of approximately 25 items and required approximately 30 minutes to complete. A copy of the instrument is included in Appendix A.

The directions for participants were written on the instrument and participants were able to record their answers on the document. The questions contained in the 
evaluation instrument were directly based on the content presented to "trained" participants.

\section{Validation}

A panel of experts validated the instrument. The panel consisted of two distinct groups. The first group included individuals responsible for delivering the training M DCPS. The second group consisted of experts from the field of Exceptional Student Education with extensive knowledge of functional assessment. Based on the information obtained from the review conducted by the first and second panel of experts revisions were made to the evaluation instrument. These revisions included the structure of the scenarios to include clearer identification of a problem behavior, and the inclusion of questions specific to the functional assessment curriculum (e.g., monitoring student behavior).

The evaluation instrument was field tested in two university settings. This field test involved students enrolled in the graduate programs in two major teacher education centers in the southeastern United Sates. Based upon the results of this field test, the evaluation instrument was once again revised. These revisions included a change to the format of the scenarios and changes to the language used in the multiple-choice questions. The scenarios were written to reflect a description of the classroom scene and a separate section identifying the problem behavior. The multiple-choice questions were altered to include language perceived to be common to a majority of special educators. These procedures yielded the final version of the evaluation instrument used for collecting data from the two groups of educational professionals. The information 
collected from these two procedures served as the process to validate the instrument for use with the sample experimental and control groups.

\section{Scoring}

\section{Rubrics for Scoring}

The primary researcher used the original rubric to score the instrument. The rubric consisted of nine variables. Each recommendation was scored using the nine variables. A score of zero was assigned if the variable was not present and a score of one was assigned if the variable was present. Each recommendation score yielded a score in the range of zero to nine. The scoring rubric is included in Appendix C.

\section{Reliability}

An observer was trained in the use of the rubric scoring system. The observer independently evaluated $12 \%$ of the documents in the sample $(n=125)$. Upon completion of the reviews, data were coded for each evaluator and checked for interrater differences, using an item - by - item analysis (this analysis is restricted to the open - ended question), and the observer calculated the differences using the formula: number of agreements/number of disagreements + disagreements x 100 . This calculation yielded an interrater reliability score. Agreement ranged from $88 \%-100 \%$.

\section{Procedure}

Administrators in Exceptional Student Education and the team responsible for the direct training of educational professionals in the M - DCPS were asked for assistance in identifying those schools with the largest numbers of special education teachers. The primary investigator visited each school site and made contact with an administrator. The administrator responsible for Exceptional Students Education services served as the 
contact and distributed the instrument. The participants were not contacted directly by the primary investigator.

During each school visit the administrator was presented with an overview of the study and three letters. The first letter came from the M-DCPS Office of Evaluations and Research, authorizing the study. The second and third letters were written by the primary researcher detailing the research intent and providing the administrators with contact information for the university (see copies of letter in Appendix C). Each participant was asked to return the completed instrument to the school - based contact. After completion of the instrument, the primary researcher returned to the school and picked up those instruments that were completed.

\section{Summary}

This study utilized an original evaluation instrument to test the ability of educators to determine the function of problem behavior, make recommendations for a behavior intervention plan, and report their knowledge of function. The data from the evaluation instrument was analyzed using a factorial ANOVA to compare trained and untrained participants according to two demographic distinctions, certification status (e.g., varying exceptionalities) and grade level taught. 


\section{CHAPTER IV}

\section{RESULTS}

The purpose of this study was to investigate the effectiveness of training educators in functional behavioral assessment on their ability to determine the function of problem behavior. The data analyzed was based on the scores obtained from 125 participants taking the Survey of Intervention Practices Used for Students Exhibiting Challenging Behavior working in $16 \mathrm{M}-$ DCPS.

\section{Demographics}

A frequency count was conducted of all participants to determine various population distributions across several categories. The Survey of Intervention Practices Used for Students Exhibiting Challenging Behavior instrument contained six demographic questions. Each question was intended to collect specific information on the professional roles participants hold in the district. In addition, specific questions were posed in relation to professional training and development.

Another frequency measure was conducted to determine the certification status of the participants. A majority of the participants $(n=70)$ were teachers certified in Varying Exceptionalities. A group of participants identified Emotional Handicaps $(n=27)$ as their primary certification, while a small number of participants $(n=28)$ indicated that they were seeking initial certification.

Comparison of Trained and Untrained Participants

A factorial ANOVA was used to compare the trained and untrained participants on the knowledge of function (multiple - choice) items and their scores for the items requiring a recommendation for a behavior intervention plan. Comparisons were made in 
two major areas. The first comparison included the assigned grade level and training status (i.e., trained or untrained). The second comparison included the participants' certification (e.g., varying exceptionalities) and training status.

Knowledge Items

As shown in Table 2 there was a significant difference in the means of the trained $(M=8.09)$ and untrained $(M=7.69)$ groups, $F(1,70)=5.54, p<.05$. This indicates that educators who received trained were better able to answer questions based on the knowledge presented in the training inspite of the grade level in which they taught.

Table 2

Grade Level and Training Status Comparison for Knowledge Items

\begin{tabular}{llcl}
\hline Source & $d f$ & $F$ & $p$ \\
\hline Grade Level (GL) & 3 & .42 & $>.10$ \\
Training Status (TS) & 1 & 5.54 & $<.05$ \\
GL x TS & 2 & .95 & $>.10$ \\
\hline
\end{tabular}

\section{Recommendation Items}

As shown in Table 3 there was not a significant difference in the means of the trained $(M=13.05)$ and untrained $(M=13.55)$ groups, $F(1,70)=2.23, p<.05$. This finding indicates that there is no difference in the quality (i.e., score) for those participants who did or did not receive training regardless of the grade level they were assigned. 
Table 3

Grade Level and Training Status Comparison for Recommendation Items

\begin{tabular}{llll}
\hline Source & $d f$ & $F$ & $p$ \\
\hline Grade Level (GL) & 3 & .34 & $>.10$ \\
Training Status (TS) & 1 & 2.23 & $>.10$ \\
GL x TS & 2 & 1.55 & $>.10$ \\
\hline
\end{tabular}

Analysis of Certification Status

In another major comparison using the factorial ANOVA the trained and untrained participants were compared according to their certification status (e.g., varying exceptionalities).

Training Status

As shown in Table 4 there was a significant difference in the means of the trained $(M=8.09)$ and untrained $(M=7.69)$ groups, $F(1,70)=20.35, p<.05$. This indicates that educators who received trained were better able to answer questions based on the knowledge presented in the training inspite of their certification status.

Table 4

Certification and Training Status Comparison for Knowledge Items

\begin{tabular}{llll}
\hline Source & $d f$ & $F$ & $p$ \\
\hline Certification Status (CS) & 2 & 7.96 & $>.10$ \\
Training status (TS) & 1 & 20.35 & $<.02$ \\
CS x TS & 2 & .33 & $>.10$ \\
\hline
\end{tabular}

As shown in Table 5 there was not a significant difference in the means of the trained $(M=13.05)$ and untrained $(M=13.55)$ groups, $F(1,70)=2.23, p<.05$. This 
finding indicates that there is no difference in the quality (i.e., score) for those participants who did or did not receive training regardless of their certification status. Table 5

Certification and Training Status Comparison for Recommendation Items

\begin{tabular}{llll}
\hline Source & $d f$ & $F$ & $p$ \\
\hline Certification Status (CS) & 2 & 10.50 & $<.10$ \\
Training Status (TS) & 1 & .00 & $>.10$ \\
CS x TS & 2 & .17 & $>.10$ \\
\hline
\end{tabular}

Knowledge of Function and Recommendation for Behavior Intervention Plan Items

There was a difference in mean scores obtained according to certification status. The original categories used in the Survey of Intervention Practices Used for Students Exhibiting Challenging Behavior instrument were "re coded" and collapsed into three categories, consisting of Varying Exceptionalities, Emotional Handicaps, and Other. This information was then used to determine the distribution of mean scores on the knowledge of function items and recommendation scores. Those teachers certified in Emotional Handicaps scored the highest on both measures, while teachers certified in Varying Exceptionalities scored the next highest and those teachers who hold certification in another area or seeking certification obtained the lowest scores of the three groups (see Table 6). 
Table 6

Mean Scores According to Certification Status

\begin{tabular}{lcll}
\hline Certification Categories & $n$ & $\begin{array}{l}\text { Multiple } \\
\text { Choice Items }\end{array}$ & $\begin{array}{l}\text { Recommendation } \\
\text { Scores }\end{array}$ \\
\hline Varying Exceptionalities & 70 & 8.13 & 13.59 \\
Emotional handicaps & 27 & 8.93 & 17.30 \\
Other areas & 28 & 7.25 & 12.11 \\
\hline
\end{tabular}

\section{Summary}

The results of this study indicate that participants who took part in the district training answered the knowledge of function multiple choice items significantly better than those who were not trained did. There was no significant difference between trained and untrained participants on the recommendation for behavior intervention plan scores. This finding offers support to the notion that district training did translate into a general knowledge of function of problem behavior for its participants. 


\section{CHAPTER V}

\section{DISCUSSION}

There are several implications for training and professional development for teachers. Educators are expected to engage in activities to continuously enhance their knowledge of general content (i.e., math, science, and social studies) and pedagogy. Each area is a fundamental requirement of the teaching profession. School districts continue to struggle with assisting teachers to translate research developments into practical applications. The legislative developments (i.e., IDEA '97) and pressure from parents and business officials to produce students who have highly developed academic and social skills compound this struggle.

As teachers continue to express concern for students who experience learning and behavioral problems, efforts to change problem behavior become essential to the functioning of schools. Whether the impetus comes from legislation or "best practice" as reported in the professional literature, school districts must be aware of how training takes place and its effects on teacher practice in schools.

Summary of Results

This study was undertaken to answer two research questions regarding the effectiveness of training teachers in functional behavioral assessment on their ability to determine the function of problem behavior. An original evaluation instrument, the Survey of Intervention Practices Used for Students Exhibiting Challenging Behavior was used to evaluate teacher's knowledge of function and ability to make recommendations to promote behavior change. 
The Miami - Dade County Public School District employed all participants as teachers or counselors. School based administrators were contacted directly for permission to evaluate teachers and counselors. All participants were contacted with the school - based administrator's assistance. The primary researcher traveled to individual schools and distributed the evaluation instruments to all willing participants.

The evaluation instrument yielded two primary measures, (a) recommendation scores (based on hypothetical scenarios) and (b) knowledge of function (based on multiplechoice questions). There was a significant difference between the multiple choice item scores ability to identify function between trained and untrained teachers. There was no significant difference in trained and untrained teachers' intervention recommendation scores.

The first research question compared trained and untrained teachers on their ability to determine function of problem behavior. Participants were further divided into categories as determined by the demographic questions contained in the evaluation instrument. The comparison categories consisted of certification status and professional assignment. There was a significant difference between the trained and untrained groups on their ability to answer knowledge of function items (multiple choice). This significant difference is present when comparing participants along several different demographic variables to include: certification status and grade level taught.

The second research question compared trained and untrained teachers on the recommendations made to promote behavior change for the hypothetical students presented in the evaluation instrument. The participants were compared along several 
different demographic items. There was no significant difference between trained and untrained participants regardless of certification status or grade level taught.

\section{Discussion}

The design of the study was posttest only. Instruments were distributed to approximately $7 \%$ of schools in the M-DCPS district. The findings of the current study indicate that the participants who were trained answered knowledge of function items significantly better than those participants who were not trained do. An essential component of training educators in the FBA technology is general knowledge of function of problem behavior (Conroy, 2000). The district training was designed to transfer knowledge of function of problem behavior. It is critical to note that this goals was accomplished according to the results of this study.

The recommendations for behavior intervention plan scores were not significantly different. This indicates that one could not discern a difference between trained and untrained participants. This finding was not in line with expectations for the results of the study. Participants who received training were expected to have the ability to develop qualitatively better interventions than those developed by participants who did not receive training. The original training session did not specifically emphasize the writing of recommendations for behavior intervention plans without the assistance of some prompt. In addition, the 3 - day format may not give participants enough content and appropriate practice in intervention development. The training format may need to be overhauled so that participant's intervention development is practiced and evaluated by experts to ensure accuracy. In light of the findings both trained and untrained participants may benefit from direct instruction and opportunity to practice intervention development. 


\section{Limitations}

The current study is limited by several factors. First, the return rate for the evaluation instruments was $25 \%$. Approximately 400 instruments were distributed in schools throughout all areas of the district; this response rate is low. A total sample size of 125 participants is represented in the $25 \%$ return rate. This smaller sample size may not represent the demographics of the general district population. Second, the mean recommendation scores are low. The rubric used to score the recommendation for behavior intervention plan scores contains a range of $0-45$. The mean score for both groups (i.e., trained and untrained) were low in consideration of the maximum scores. This may be explained by several reasons. First, participants may have need additional time to understand and then apply the knowledge gained in the FBA training. Participants may have simply been ill prepared to apply their knowledge of function to develop recommendations for behavior intervention plans. Second, the district-sponsored training took place over a 3-day period. These 3 days may have not been "strong enough" to assist participants to gain knowledge and the ability to apply the knowledge to make a quality recommendation for the behavior intervention plan. Finally, the response format of the evaluation instrument may have influenced the quality of the recommendations. The open - ended format required participants to formulate an answer completely independently. If participants were confident in their ability to generate recommendations without the assistance of any prompts, their responses were weak.

\section{Implications for Practice}

The learning and behavioral needs of children with disabilities is a point of concern for many teachers in special and general education. Many teachers seek 
additional training and support to offer programming that allows children with disabilities to enter or stay in the general education classroom. Students with disabilities are also transferred out of general education classrooms via teacher's requests for various reasons. Professional development made available to teachers intended to change practice is commonplace in school districts. What is not commonplace is a direct evaluation of such training to gain some insight into the effectiveness of translating the training content into teacher practice. Further, there is rarely a direct inquiry into the effect of the training on teacher work patterns as they implement the training initiative.

There are several implications related to the current study. One, educators need direct assistance when applying the knowledge gained from a district training. School based personnel need the direct assistance of "expert personnel" to have opportunities to design, implement, and evaluate the application of a new method (i.e., FBA). These outside experts should be made available for an extended period to ensure mastery of the skills gained in the original district training session. Two, district sponsored training must require that teachers engage in application activities during the initial training session. This "first step" will allow for teachers to practice the required action necessary after completing the training. Teachers do not have the opportunity to "use the method" if this opportunity is not provided in the training session. The current training model assumes that teachers will use the FBA technology in a reactionary mode, only to be used when a functional behavioral assessment is required. In this case the teacher is "learning on the job." This situation can be avoided with ample practice opportunities in the initial training session as well as practice opportunities with the on - site expert. 
The problem behavior present in schools is currently viewed in a greater context of school violence that many perceive to be on the rise. Behavior that is harmful to an individual herself or others is viewed as a serious matter. Teachers should be well equipped to handle problem behaviors in and around the classroom and other school areas. Techniques for promoting positive social interactions between students and adults should be readily and widely available to assist teachers to directly teach positive behavior.

\section{Recommendations for Further Research}

This study was designed to gather information about teacher's knowledge level of function behavioral assessment and the recommendation that teachers would make when faced with a problem behavior. There are a number of directions for future research in functional behavioral assessment in schools. Other studies that would add to the body of knowledge about functional behavioral assessment in school include:

1. Replication of this study in another school district. This study would require the use of a revised evaluation instrument. The instrument used for this replication would require the participation of officials from the school district with extensive knowledge of the training program used in the district. The instrument should directly reflect the content taught in the functional behavioral assessment training program. Also, a number of teachers should be identified prior to the beginning of the study to ensure a significant number of participants

2. A document survey should be conducted to examine the actual Behavior Intervention Plans (BIPs) being used by teachers in schools. This study will require that an evaluation tool is developed to develop a scoring system for the 
BIPs. Each BIP should be evaluated for its hypothesis statement, replacement behavior, recommended intervention, and monitoring system. This study should give some indication of the actual practices teachers are utilizing in schools to promote behavior change.

3. Investigate the amount of time teachers spend conducting a functional behavioral assessment in schools. A random selection of schools on the elementary, middle and high school schools will allow a good cross section of functional behavioral assessments conducted in schools. Direct observation of teachers and records of duration (time spent actually collecting data, developing a hypothesis statement, and planning an intervention) for each child in the school over a specified period will give some information as to the actual "costs" of functional behavioral assessment in regards to teacher time.

4. A replication of this study conducted in the same school district while altering the response formats of the evaluation instrument. The current evaluation instrument required participants to write a recommendation for behavior change without the assistance of a prompt or predetermined answers. This response format also limited those who would prefer not to write at all, but rather type or orally repot answer. If the instrument is changed perhaps the number of participants willing to make a recommendation will increase as well as the diversity and complexity of the responses may increase. This information may offer further insight into teacher practice in relation to promoting behavior change. 


\section{Conclusion}

The reauthorization of IDEA' 97 is the catalyst for major changes in the discipline procedures used for students with disabilities (Yell, 1998). The rise in school violence and concerns for the safety of all students in schools has been highly influential in directing the way in which educators respond to problem behavior in schools (Sugai et al., 1996). IDEA ' 97 requires educators to use FBA as a pre - intervention procedure before developing an intervention. This change in policy is calling for a change in practice (Nelson, 1997); The change in policy requires training to ensure that educators are not only aware of the change in legislation, but also aware and able to implement the practice (Conroy, 2000).

Many questions have been raised about the ability of teachers to implement the new FBA practice (Gable, 1995; Nelson, 1997; Conroy, 2000). In this study an evaluation instrument was developed to test educators on three critical features of the new FBA practice: (a) general knowledge of function, (b) ability to determine the function of problem behavior and (c) make recommendations for a behavior intervention plan. Each of these measures is critical to utilizing the FBA technology for the benefit of students. The results of the study indicate that participants who are trained in the FBA method do gain a general knowledge of function of problem behavior. This lays a foundation for the use of the technology. In order to make from the traditional response to behavior (i.e., suspension), it is necessary to understand the philosophy of functional assessment. Indications are that the training is successful in assisting educators gain a knowledge of function. This "first step" may be beneficial for school districts to build upon this and further assist educators in their ability to apply the FBA technology. 
Inservice training is one of the most common methods for educators to gain an understanding of new ideas, methods, and or initiatives they will be held responsible for in the future. This study validates the current model, but also questions the same model. The inservice training was not sufficient in its current form to assist educators to gin the understanding necessary to apply the knowledge to recommendations for behavior intervention plans. This "last step" is crucial for future training. The district training has made significant strides towards assisting educators learn a beneficial method for behavior change. It is important that staff development does not stop with general knowledge, but continues so that educators can learn to apply their knowledge to development sound behavioral interventions. 


\section{List of References}

Alber, S. R. \& Heward, W. L. (1996). "Gotcha!" Twenty - five behavior traps guaranteed to extend your students' academic and social skills. Intervention in School and Clinic, 31(5), $285-289$.

Anderson, J. L., Albin, R. W., Mesaros, R. A., Dunlap, G., \& Morelli - Robbins, M. (1993). Issues in providing training to achieve comprehensive behavioral support. In J. Reichle \& D. P. Wacker (Eds.), Communicative alternatives to challenging behavior: Integrating functional assessment and intervention strategies. Vol. 3. Communication and language intervention series. (pp. 363 - 406). Brookes Publishing: Baltimore, MD.

Bambara, L. M., Mitchell - Kvacky, N. A., \& Iacobelli, S. (1994). Positive behavioral support for students with severe disabilities: An emerging multicomponent approach for addressing challenging behaviors. School Psychology Review, 23(2), $263-278$.

Bender, W. N. \& McLaughlin, P. J. (1997). Violence in the classroom: Where we stand. Intervention in School and Clinic, 32(4), $196-198$.

Buggey, T. (1999). "Look! I'm on tv!" Using self - monitoring to change behavior. Teaching Exceptional Children, 31(4), 27 - 30.

Carpenter, S. L., \& McKee - Higgins, E. (1996). Behavior management in the inclusive classrooms. Remedial and Special Education, 17(4), 195 - 203.

Carnine, D. (1997). Bridging the research - to - practice gap. Exceptional Children, 63 (4), $513-521$.

Carr, E. G. (1977). The motivation of self - injurious behavior: A review of some hypotheses. Psychological Bulletin, 84(4), 800 - 816.

Carr, E. G. \& Durand, V. M. (1985). Reducing problem behavior through functional communication training. Journal of Applied Behavior Analysis, 18(3), 111 - 126.

Carr, E. G. (1994). Emerging themes in the functional analysis of problem behavior. Journal of Applied Behavior Analysis, 27(2), 393 - 399.

Carr, E. G., Dunlap, G., Horner, R. H., Koegel, R. L., Turnball, A. P., Sailor, W., Anderson, J. L., Albin, R. W., Koegel, L. K., \& Fox, L. (2002). Positive behavior support: Evolution of an applied science. Journal of Positive Behavior Interventions, $4(1), 4-16,20$. 
Colvin, G. (1993). Reconceptualizing behavior management and school - wide discipline in general education. Education and Treatment of Children, 16(4), 361 -381 .

Conroy, M. A. \& Davis, C. A. (2000).Early elementary - aged children with challenging behaviors: Legal and educational issues related to IDEA and assessment. Preventing School Failure, 44(4), 163 - 168.

Conroy, M. A., Clark, D., Gable, R. A., \& Fox, J. J. (1999). Building competence in the use of functional behavioral assessment. Preventing School Failure, 43(4), 140 144.

Davis, C. A. (1998). Functional assessment: Issues in implementation and applied research. Preventing School Failure, 43(1), 34-36.

Day, H. M., Horner, R. H., \& O'Niell, R. E. (1994). Multiple functions of problem behaviors: Assessment and intervention. Journal of Applied Behovior Analysis, $27(2), 279-289$.

Drasgow, E., Yell, M. L., Bradley, R., \& Shriner, J. G. (1999). The idea amendments of 1997: A school - wide model for conducting functional behavioral assessments and developing behavior intervention plans. Education and Treatment of Children, 22 (3), 244-266.

Ellis, J., \& Magee, S. K. (1999). Determination of environmental correlates of disruptive classroom behavior: Integration of functional analysis into public school assessment. Education and Treatment of Children, 22(3), 291 - 316.

Englert, C. S. (1984). Measuring teacher effectiveness from the teacher's point of view. Focus on Exceptional Children, 17(2), 1-15.

Fantuzzo, J., \& Atkins, M. (1992). Applied behavior analysis for educators: Teacher centered and classroom based. Journal of Applied Behavior Analysis, 25(1), 37 42.

Foster - Johnson, L., \& Dunlap, G. (1993). Using functional assessment to develop effective, individualized interventions for challenging behaviors. Teaching Exceptional Children, 66(1), 44-50.

Fowler, R. C., \& Schnacker, L. E. (1994). The changing character of behavioral assessment and treatment: An historical introduction and review of functional analysis research. Diagnostique, $19(2-3), 79-102$. 
Fox, J., Conroy, M., \& Heckaman, K. (1998). Research issues in functional assessment of the challenging behaviors of students with emotional and behavioral disorders. Behavioral Disorders, 24(1), 26-33.

Gable, R. A. (1999). Functional assessment in school settings. Behavioral Disorders, 24 (3), 246-248.

Gable, R. A., Hendrickson, J. M., \& Smith, C. (1999). Changing discipline policies and practices: Finding a place for functional assessment in schools. Preventing School Failure, 43(4), $167-170$.

Gable, R. A., Quinn, M. M., Rutherford, R. B., \& Howell, K. (1998). Addressing problem behaviors in schools: Use of functional assessments and behavior intervention plans. Preventing School Failure, 42(3), 106 - 113.

Gersten, R. \& Brenglman, S. U. (1996). The quest to translate research into classroom practice. Remedial and Special Education, 17(2), 67-74.

Gettinger, M. (1988). Methods of proactive classroom management. School Psychology Review, $17(2), 227-242$.

Greenwood, C. R. \& Abbott, M. (2001). The research to practice gap in special education. Teacher Education and Special Education, 24(4), 276 - 289.

Gresham, F. R., Quinn, M. M., \& Restori, A. (1999). Methodological issues in functional analysis: Generalizability to other disability groups. Behavioral Disorders, 24(2), $180-182$.

Gunter, P. L., \& Reed, T. M. (1996). Self-evaluation of instruction: A protocol for functional assessment of teaching behavior. Intervention in School and Clinic, 31 (4), $225-230$.

Hall, A. M. \& Belifore, P. J. (1997). Reduction of aggressive behaviors with changes in activity: Linking descriptive and experimental analyses. Education and Training in Mental Retardation and Developmental Disabilities, 32(4), 331 - 339.

Hartwig, E. P., \& Ruesch, G. M. (2000). Disciplining students in special education. The Journal of Special Education, 33(4), $240-247$.

Hendrickson, J. M., Gable, R. A., Conroy, M. A., Fox, J., \& Smith, C. (1999).

Behavioral problems in schools: Ways to encourage functional assessment (FBA) of discipline - evoking behavior of students with emotional and/or behavioral disorders (EBD). Education and Treatment of Children, 22(3), 280-290. 
Horner, R. H., Dunlap, G., Koegel, R. L., Carr, E. G., Sailor, W., Anderson, J., Albin, R. W., \& O'Neill, R. E. (1990). Toward a technology of "nonaversive" behavioral support. Journal for the Association for Persons with Severe Handicaps, 15(3), $125-132$.

Horner, R. H. (1994). Functional assessment: Contributions and future directions. Journal of Applied Behavior Analysis, 27(2), 401 - 404.

Horner, R. H. (2000). Positive behavior supports. Focus on Autism and Other Developmental Disabilities, 15(2), 97-105.

Ishii - Jordan, S. R. (2000). Behavioral interventions used with diverse student. Behavioral Disorders, 25(4), 299-309.

Iwata, B. A., Dorsey, M. F., Slifer, K. J., Bauman, K. E., \& Richman, G. S. (1982). Toward a functional analysis of self - injury. Analysis and Intervention in Developmental Disabilities, 2, 3-20.

Johns, B. H. (1998). What the new individuals with disabilities education act (IDEA) means for students who exhibit aggressive or violent behavior. Preventing School Failure, 42(3), 102-105.

Kauffman, J. M. (1996). Research to practice issues. Behavioral Disorders, 22(1), 55 60.

Kauffman, J. M. (1997). Caricature, science, and exceptionality. Remedial and Special Education, 18(3), $130-132$.

Keel, M. C., Dangel, H. L., \& Owens, S. H. (1999). Selecting instructional interventions for students with mild disabilities in inclusive classrooms. Focus on Exceptional Children, 31(8),1-16.

Knoster, T. P. (2000). Practical application of functional behavioral assessment in schools. Journal for the Association for Persons with Sever Handicaps, 25(4), 201 -211 .

Kratochwill, T. R., \& McGivern, J. E. (1996). Clinical diagnosis, behavioral assessment, and functional analysis: Examining the connection between assessment and intervention. School Psychology Review, 25(3), 342-355.

Larson, P. J. \& Maag, J. W. (1998). Applying functional assessment in general education classrooms issues and recommendations. Remedial and Special Education, 19(6), $338-349$. 
Lewis, T. J., Sugai, G. \& Colvin, G. (1998). Reducing problem behavior through a school - wide system of effective behavioral support: Investigation of a school wide social skills training program and contextual interventions. School Psychology Review, 27(3), 446 - 459.

Lewis, T. J. \& Sugai, G. (1999). Effective behavior support: A systems approach to proactive schoolwide management. Focus on Exceptional Children, 31(6), 1 - 24.

Maag, J. W. (2001). Rewarded by punishment: Reflections on the disuse of positive reinforcement in schools. Exceptional Children, 67 (2), $173-186$.

Morgan - D' Atrio, C., Northup, J., LaFleur, L., \& Spera, S. (1996). Toward perspective alternatives to suspensions: A preliminary evaluation. Behavioral Disorders, 21 (2), $190-200$.

Munk, D. D. \& Repp, A. C. (1994). The relationship between instructional variables and problem behavior: A review. Exceptional Children, 60(5), 390 - 401.

Murdick, N. \& Gartin, B. C. (1999). Complying with idea: Using functional assessment of behavior to plan programs for students with mental retardation. Education and Training in Mental Retardation and Developmental Disabilities, 34(4), 464 - 472.

Neef, N. A., \& Iwata, B. A. (1994). Current research on functional analysis methodologies: An introduction. Journal of Applied Behavior Analysis, 27(2), 211 -214 .

Nelson, C. M. (1997). Aggressive and violent behavior: A personal perspective. Education and training of Children, 20(3), 250 - 262.

Nelson, J. R., Roberts, M. L., Rutherford, R. B., Mathur, S. R., \& Aaroe, L. A. (1999). A statewide survey of special education administrators and school psychologist regarding functional behavioral assessment. Education and Treatment of Children, 22(3), $267-279$.

O'Brien, S. \& Repp, A. C. (1990). Reinforcement - based reductive procedures: A review of 20 years of their use with persons with severe or profound retardation. Journal for the Association for Persons with Sever Handicaps, 15(3), 148 - 159.

Peck, J., Sasso, G. M., \& Stambaugh, M. (1998). Functional analysis in the classroom: Gaining reliability without sacrificing validity. Preventing School Failure, 43(1), $14-18$.

Penno, D. A., Frank, A. R., \& Wacker, D. P. (2000). Instructional accommodations for adolescent students with severe emotional or behavioral disorders. Behavioral Disorders, 25(4), 325 - 343. 
Quinn, M. M. (2000). Functional behavioral assessment: The letter and spirit of the law. Preventing School Failure, 44(4), 147 - 151.

Reid, R. \& Maag, J. W. (1998). Functional assessment: A method for developing classroom - based accommodations and interventions for children with adhd. Reading \& Writing Quarterly: Overcoming Learning Difficulties, 14(9), 9-42.

Reitz, A. L. (1994). Implementing comprehensive classroom - based programs for students with emotional and behavioral problems. Education and Treatment of Children, $17(3), 312-331$.

Reyna, C. (2000). Lazy, dumb, or industrious: When stereotypes convey attribution information in the classroom. Educational Psychology Review, 12(1), 85 - 110.

Rogers, E. L. (1998). Functional assessment in the home. Preventing School Failure, 43 (1), $31-33$.

Sasso, G. M., Peck. J., \& Garrison - Harrell, L. (1998). Social interaction setting events: Experimental analysis of contextual variables. Behavioral Disorders, 24(1), 34 43.

Schill, M. T., Kratochwill, T. R. \& Elliott, S. N. (1998). Functional assessment in behavioral consultation: A treatment utility study. School Psychology Review, 13(2), $116-140$.

Scott, B. J., Vitale, M. R., \& Masten, W. G. (1998). Implementing instructional adaptations for students with disabilities in inclusive classrooms. Remedial and Special Education, 19(2), $106-199$.

Scotti, J. R., Evans, I. M., Meyer, L. H., \& Walker, P. (1991). A meta - analysis of intervention research with problem behavior: Treatment validity and standards of practice. American Journal of on Mental Retardation, 96(3), 233 - 256.

Scott, T. M., \& Nelson, C. M. (1999). Functional assessment: Implications for training and staff development. Behavioral Disorders, 24(3), 249-252.

Shellady, S. \& Stichter, J. P. (1999). Training preservice and inservice educators to conduct functional assessments: Initial issues and implications. Preventing School Failure, 43(4), 154-159.

Simeonsson, R. J., Bailey, D., Smith, T., \& Buysse, V. (1995). Young children with disabilities: Functional assessment by teachers. Journal of Developmental and Physical Disabilities, 7(4), $267-284$. 
Soodak, L. C. (1994). Teachers' thinking about difficult - to - teach students. Journal of Educational Research, 88(1), 44-51.

Stickney, M. L., \& Miltenberger, R. G. (1998). School refusal behavior: Prevalence, characteristics, and the schools' response. Education and Treatment of Children, $21(2), 160-170$.

Sugai, G., Horner, R. H., \& Sprague, J. R. (1999). Functional - assessment - based behavior support planning: Research to practice to research. Behavioral Disorders, 24(3), $253-257$.

Sugai, G., Plamer - Lewis, T., \& Hagan, S. (1998). Using functional assessments to develop behavior support plans. Preventing School Failure, 43(1), 6-12.

Symons, F. J., McDonald, L. M., \& Wehby, J. H. (1998). Functional assessment and teacher collected data. Education and Treatment of Children, 21(2), 135 - 159.

Taylor, J. C., \& Romanczyk, R. G. (1994). Generating hypothesis about the function of student problem behavior by observing teacher behavior. Journal of Applied Behavior Analysis, 27(2), 251 - 265.

Theall, M. (1999). New directions for theory and research on teaching: A review of the past twenty years. New Directions for Teaching and Learning, 80, 29-52.

Tollefson, N. (2000). Classroom applications of cognitive theories of motivation. Educational Psychology Review, 12(1),63-83.

Umbreit, J. (1995). Functional analysis of disruptive behavior in an inclusive classroom. Journal of Early Intervention, 20(1), $18-29$.

Umbreit, J. (1995). Functional assessment and intervention in a regular classroom setting for the disruptive behavior of a student with attention deficit hyperactivity disorder. Behavioral Disorders, 20(4), $267-278$.

Vaughn, B. J., \& Horner, R. H. (1997). Identifying instructional tasks that occasion problem behaviors and assessing the effects of student versus teacher choice among these tasks. Journal of Applied Behavior Analysis, 30(2), 299-312.

Vollmer, T. R., Marcus, B. A., Ringdahl, J. E., \& Roane, H. S. (1995). Progressing from brief assessments to extended experimental analyses in the evaluation of aberrant behavior. Journal of Applied Behavior Analysis, 28(4), 561 - 576.

Wagner, M. (1991). Youth with disabilities: How are they doing? The national Longitudinal Transition Study of Special Education Students. Melno Park CA: SRI International. 
Watson, T. S., Ray, K. P., Turner, H. S., \& Logan, P. (1999). Teacher - implemented functional analysis and treatment: A method for linking assessment to intervention. School Psychology Review, 28(2), 292 - 302.

Weigle, K. L. (1997). Positive behavior support as a model for promoting educational inclusion. Journal for the Association for Persons with Severe Handicaps, 22(1), $36-48$.

Yell, M. L. \& Katsiyannis, A. (2000). Functional behavioral assessment and idea 1997: Legal and practice considerations. Preventing School Failure, 44(4), 158 - 162.

Yell, M. L., Rozalski, M. E., \& Drasgow, E. (2001). Disciplining students with disabilities. Focus on Exceptional Children, 33(9), 1 - 20.

Zimmerman, B. F. (1998). Classroom disruption: Educational theory as applied to perception and action in regular and special education. Advances in Special Education, 11(1), 77 - 98 .

Zurkowski, J., Kelly, P. S., \& Griswold, D. E. (1998). Discipline and idea 1997:

Instituting a new balance. Intervention in School and Clinic, 34(1), 3-9. 
APPENDIXES 
APPENDIX A 
Survey of intervention Practices Used for Students Exhibiting Challenging Behavior Section \# 1

Read the following statements. Then circle the answer that best completes the statement. 1. Circle the letter that best describes your certification

a. Certification in special education (e.g., varying exceptionalities)

b. Certification in emotional handicap

c. Seeking certification in special education

d. Write in other area of certification

2. Circle the letter that best describes your professional assignment

a. Classroom serving students with disabilities only

b. Classroom serving students with disabilities and students without disabilities

c. Counselor serving students with disabilities only

d. Counselor serving students with and without disabilities

3. Circle the letter that best corresponds to the grades of the students whom you teach

a. Pre - school (Pre - K)

b. Elementary students $(\mathrm{K}-5)$

c. Middle students $(6-8)$

d. High school students $(9-12)$

e. Classroom has students in multiple grade levels

4. Circle the letter that corresponds to the year in which you received the Miami-Dade County Public Schools training Functional Assessment of Behavior training

a. School year $1997-1998$

b. School year $1998-1999$

c. School year 1999-2000

d. Did not receive Miami - Dade County Public Schools Functional Assessment of Behavior training

5. Circle the letter that corresponds to the years of experience you have in education.
a. $0-3$
b. $4-7$
c. $8-11$
d. $12-17$
e. $18+$ 
6. Circle the letter that corresponds to any specialized behavioral training you may have

a. Certified Behavior Analyst (i.e., CBA)

b. Certified Associate Behavior Analyst (i.e., CABA)

c. University course work in Applied Behavior Analysis

d. District sponsored training in Applied Behavior Analysis (other than MDCPS FAB training)

e. Other training in Applied Behavior Analysis

f. Other training in $\mathrm{FAB}$ 


\section{Section \# 2}

Read the following scenario. At the end of the passage, circle the answer that best describes the function of behavior exhibited by the student.

7. Scenario: John is a third grade student with learning disabilities in a self - contained classroom with one special education teacher and an instructional aide. John reads below grade level. On a typical day the teacher assigns four different tasks requiring students to read. The class is given instruction in a specific topic area and then required to work independently. The teacher gives the instructions for the independent task and then requires students to work at their desks. During the lesson presentation and the guided practice portion of the lesson, the teacher circulates throughout the classroom to monitor students while they work. Whenever the teacher approaches John to assist him, he does not exhibit any problem behavior.

Problem behavior: The I.E.P. team has observed that during independent work periods when the teacher is assisting other students John often calls the teacher "names." The teacher immediately verbally responds to John and/or moves in closer proximity to him in response to the name-calling.

What is the most likely function that John's behavior serves?
a. Get attention
b. Get rewards/activities
c. Get sensory feedback
d. Escape peers/adults
e. Escape tasks
f. Escape personal states

Now answer the following question in relation to an intervention appropriate for John.

Provide a recommendation to the teacher for an intervention most likely to result in effective (i.e., rapid and semi - permanent) control of John's problem behavior.

8. Scenario: Mary is an eighth grade student with mental retardation who attends four special education courses with one special education teacher and an instructional aide. On a typical day the special education teacher requires Mary to engage in two to three guided tasks and two to three independent tasks. Mary is actively involved in most of her non-academic tasks (i.e., vocational preparation). Mary does not show the same enthusiasm for the academic tasks.

Problem behavior: The I.E.P. team has determined that Mary is not attentive during academic task presentations. She pushes papers off of her desk and yells out to the teacher and/or aide that, "academics are stupid." Even after the papers are placed back on the desk, she continuously seeks assistance after the teacher or instructional aide has left her side. The assistance Mary seeks is not related to the task, but rather 
requests for the restroom or snacks. Mary does not complete any portion of her academic tasks.

What is the most likely function that Mary's behavior serves?
a. Get attention
b. Get rewards/activities
c. Get sensory feedback
d. Escape peers/adults
e. Escape tasks
f. Escape personal states

Now answer the following question in relation to an intervention appropriate for Mary.

Provide a recommendation to the teacher for an intervention most likely to result in effective (i.e., rapid and semi - permanent) control of Mary's problem behavior.

9. Scenario: Chuck is an eleventh grade student with autism in a specialized classroom for students with autism, with one teacher and two instructional aides. Chuck is working on several pre - vocational skills that allow him to work hands - on in the classroom. Chuck is successful with many of the tasks and earns rewards from the "treasure chest" upon completion of his tasks. Chuck must take his completed task to the finished table and then inform the teacher or one of the instructional aides that he is finished.

Problem behavior: The I.E.P. team is concerned with the following problem behavior: Chuck has associated the finish table with rewards. While Chuck does complete $80 \%$ of his tasks, on some occasions he will still go to the finish table and request a reward. The teachers and aides re - direct Chuck to complete his work, but Chuck yells and kicks the table when he does not receive a reward after going to the finish table.

What is the most likely function that Chuck's behavior serves?
a. Get attention
b. Get rewards/activities
c. Get sensory feedback
d. Escape peers/adults
e. Escape tasks
f. Escape personal states

Now answer the following question in relation to an intervention appropriate for Chuck.

Provide a recommendation to the teacher for an intervention most likely to result in effective (i.e., rapid and semi - permanent) control of Chuck's problem behavior. 
10. Scenario: Susie is a fifth grade student with emotional handicaps in a co - taught general education classroom with one general education teacher and one special education teacher. Susie is working on grade level in all of the academic subject areas. Susie works well with the general education teacher and appropriately seeks her assistance when needed. Susie does not work well with the special education teacher. She is not willing to follow simple requests or even sit in close proximity to the special education teacher. The general education teacher reminds Susie is that she cannot work with one teacher exclusively.

Problem behavior: The I.E.P. team is concerned with the following problem behavior: When the special education teacher attempts to assist Susie she gets out of her seat and yells for the attention of the general education teacher. Susie does not complete her task and calls the special education teacher names while running around the classroom. Susie says, "I only like girls," and will speak to the special education teacher who is man.

What is the most likely function that Susie's behavior serves?
a. Get attention
b. Get rewards/activities
c. Get sensory feedback
d. Escape peers/adults
e. Escape tasks
f. Escape personal states

Now answer the following question in relation to an intervention appropriate for Susie.

Provide a recommendation to the teacher for an intervention most likely to result in effective (i.e., rapid and semi - permanent) control of Susie's problem behavior.

11. Scenario: Tommy is a sixth grade student with mental retardation in a self - contained classroom with one special education teacher and two instructional aides. Tommy is primarily working on social skills that will allow him to attend community-based instruction. Tommy is learning how to start a conversation with another individual. Tommy holds his hands and rub them together on a continuous basis and will not release his hands to wave or shake hands.

Problem behavior: The I.E.P. team is concerned with the following problem behavior: Tommy rubs his hands together almost the entire day. Tommy is told to keep his hands in his lap and then he is given a piece of candy if he complies. While this works for a short period, Tommy seems to enjoy rubbing his hands together even during instruction of social skills. 
What is the most likely function that Tommy's behavior serves?
a. Get attention
b. Get rewards/activities
c. Get sensory feedback
d. Escape peers/adults
e. Escape tasks
f. Escape personal states

Now answer the following question in relation to an intervention appropriate for Tommy.

Provide a recommendation to the teacher for an intervention most likely to result in effective (i.e., rapid and semi - permanent) control of Tommy's problem behavior. 


\section{Section \# 3}

Read each of the following questions. Then circle the answer that best completes the statement.

12. The underlining notion of a Functional Assessment of Behavior is that all behaviors ?
a. serve a purpose.
b. are symptoms of a disability.
c. are based on medical factors.
d. are controlled by the environment.
e. cannot be changed.

13. Many of the behaviors people engage in provide some sort of "payoff." This "payoff" is referred to as
a. negative reinforcement.
b. delayed reinforcement.
c. positive reinforcement.
d. intermittent reinforcement.
e. differential reinforcement.

14. In schools many children may "communicate" their dissatisfaction with people, places, or demands of an environment through problem behaviors. This "communication" is referred to as
a. negative reinforcement.
b. delayed reinforcement.
c. positive reinforcement.
d. intermittent reinforcement.
e. differential reinforcement.

15. One of the critical features of a behavior intervention plan is that the chosen intervention
a. punish the student.
b. match the function.
c. remove the student from class.
d. involve the parent.
e. involve the school site administrator. 
16. If a behavior intervention plan is designed to teach students a skill as opposed to implementing traditional management procedures, the plan is using a(n)
a. effective punishment procedure.
b. number of techniques at one time.
c. school approved behavior management plan.
d. instructional model.
e. district wide behavior management plan. 
APPENDIX B 


\section{Rubric}

\begin{tabular}{|c|c|}
\hline Area of Intervention & Scoring System \\
\hline $\begin{array}{l}\text { 1. The recommended intervention matches the } \\
\text { function of the problem behavior. }\end{array}$ & $\begin{array}{l}(0)=\text { The recommendation does not } \\
\text { contain this element. } \\
(1)=\text { The recommendation does } \\
\text { contain this element. }\end{array}$ \\
\hline 2. The recommended intervention is positive. & $\begin{array}{l}(0)=\text { The recommendation does not } \\
\text { contain this element. } \\
(1)=\text { The recommendation does } \\
\text { contain this element. }\end{array}$ \\
\hline $\begin{array}{l}\text { 3. The recommendation indicates an acceleration } \\
\text { target versus a deceleration target (i.e., the target } \\
\text { behavior will be increased versus reduction } \\
\text { motivated target behavior). }\end{array}$ & $\begin{array}{l}(0)=\text { The recommendation does not } \\
\text { contain this element. } \\
(1)=\text { The recommendation does } \\
\text { contain this element. }\end{array}$ \\
\hline $\begin{array}{l}\text { 4. The intervention indicates that some instruction } \\
\text { or activities in support of instruction will take place. }\end{array}$ & $\begin{array}{l}(0)=\text { The recommendation does not } \\
\text { contain this element. } \\
(1)=\text { The recommendation does } \\
\text { contain this element. }\end{array}$ \\
\hline $\begin{array}{l}5 . \text { The recommendation indicates that more than } \\
\text { more person (i.e., a team) is responsible for } \\
\text { planning, implementing, monitoring, or revising the } \\
\text { recommendation. }\end{array}$ & $\begin{array}{l}(0)=\text { The recommendation does not } \\
\text { contain this element. } \\
(1)=\text { The recommendation does } \\
\text { contain this element. }\end{array}$ \\
\hline $\begin{array}{l}\text { 6. The recommendation does not indicate any use of } \\
\text { punitive measures. }\end{array}$ & $\begin{array}{l}(0)=\text { The recommendation does not } \\
\text { contain this element. } \\
(1)=\text { The recommendation does } \\
\text { contain this element. }\end{array}$ \\
\hline $\begin{array}{l}\text { 7. The recommendation indicates that some form of } \\
\text { monitoring will take place. }\end{array}$ & $\begin{array}{l}(0)=\text { The recommendation does not } \\
\text { contain this element. } \\
(1)=\text { The recommendation does } \\
\text { contain this element. }\end{array}$ \\
\hline $\begin{array}{l}\text { 8. The recommendation is applicable to school } \\
\text { settings. }\end{array}$ & $\begin{array}{l}(0)=\text { The recommendation does not } \\
\text { contain this element. } \\
(1)=\text { The recommendation does } \\
\text { contain this element. }\end{array}$ \\
\hline $\begin{array}{l}\text { 9. The recommended intervention is based on one or } \\
\text { more of the } 7 \text { guiding questions (e.g., } \\
\text { communication training, and explicit } \\
\text { reinforcement). }\end{array}$ & $\begin{array}{l}(0)=\text { The recommendation does not } \\
\text { contain this element. } \\
(1)=\text { The recommendation does } \\
\text { contain this element. }\end{array}$ \\
\hline $\begin{array}{l}\text { Total recommendation score (add the scores from } \\
\text { each of the recommendation questions and write in } \\
\text { space provided) }\end{array}$ & $\begin{array}{l}7 .+9 . \\
10 . \quad 11 . \\
\text { Total } \quad 12 . \\
\end{array}$ \\
\hline
\end{tabular}


APPENDIX C 
Charles Dukes, EdD Candidate

Florida international University

Department of Educational Psychology/Research - ZEB - \#214

11200 SW $8^{\text {th }}$ Street

Miami, Florida 33169

Teachers and Counselors

Miami - Dade County Public Schools

Dear Potential Participant,

I am currently conducting research in the Miami - Dade County Public Schools (M - DCPS). This research involves the district sponsored training in the techniques of Functional Assessment of Behavior (FAB). This training has been taking place in the district for the past three school years. This study utilizes a test to gather information on the ability of teachers and school counselors to determine the function of problem behavior and to make recommendations to change problem behavior. Personnel trained and not trained in FAB will be asked to complete this instrument. This letter along with a copy of the instrument will be sent to approximately five hundred teachers and school counselors throughout the district. The results of this study will benefit school personnel by providing information about the general knowledge level of personnel in relation to $\mathrm{FAB}$ techniques and common recommendations personnel use to influence behavioral change. There is the potential for school personnel to sacrifice instructional or personal time by completing the instrument. The time sacrificed should be reduced with the collaborative efforts of school level principals allowing for completion of the instrument.

The information obtained from the instrument will be confidently and can not be directly linked to any school personnel. Participation in this study does not involve any more than "minimal risk" or the common risks one faces in everyday life. The instruments will be maintained in an office with only myself (primary researcher) having access. Participation in this study is completely voluntary and you may refuse to complete this instrument. Refusal to complete this instrument will not impact your professional evaluation or duties in M-DCPS.

Thank you,

Charles Dukes

PS: If you have questions about this research, you may contact me at (305) 622-2624 or please feel free to contact Dr. Bernard Gerstman, Chairman of Florida International University Institutional Review Board at $(305)-348-3115$. 
Charles Dukes, EdD Candidate

Florida international University

Department of Educational Psychology/Research - ZEB - \#214

11200 SW $8^{\text {th }}$ Street

Miami, Florida 33169

School Principal

Miami - Dade County Public Schools

Dear School Principal,

I am currently conducting research in the Miami - Dade County Public Schools (M-DCPS). This research involves the district sponsored training in the techniques of Functional Assessment of Behavior (FAB). This training has been taking place in the district for the past three school years. This study utilizes a test to gather information on the ability of teachers and school counselors to determine the function of problem behavior and to make recommendations to change problem behavior. Personnel trained and not trained in FAB will be asked to complete this instrument. This letter along with a copy of the instrument will be sent to approximately three thousand teachers and school counselors throughout the entire district.

I am writing to you to institute a two step process for completion of this study. Enclosed in this packet you will find a list of teachers and school counselors who have and have not received training in FAB. Please distribute the informed consent letters and the instruments to those indicated on the respective list. Upon completion of the instruments participants should return them to the office manager and in - turn this envelope will be returned to the Biscayne Building.

Your assistance with this study is greatly beneficial to my interests and work in teacher training efforts and beneficial to $\mathrm{M}$ - DCPS in their efforts to continue to provide the highest quality staff development.

Thank you,

\section{Charles Dukes}

PS: If you have questions about this research, you may contact me at (305) 622-2624 or please feel free to contact Dr. Bernard Gerstman, Chairman of Florida International University Institutional Review Board at $(305)-348-3115$. 


\section{VITA}

Charles Dukes

Education

Ed. D. Candidate Florida International University, Miami, Florida

Special Education (Major area of study)

Curriculum and Instruction (Cognate)

M. Ed. University of Houston, Houston, Texas

Special Education

December 1994

BS

Florida Agricultural and Mechanical University, Tallahassee, Florida Psychology (Major) Religion (Minor)

April 1992

BS

Florida Agricultural and Mechanical University, Tallahassee, Florida Philosophy (Major) Religion (Minor)

April 1992

Credentials and Licensure

State of Texas

Generic Special Education

State of Florida Exceptional Student Education - Varying Exceptionalities

Psychology

Social Studies Grades 6 through 12

Professional Experiences

Site Coordinator

Education

The University of Miami Center for Autism and Related Disabilities (C.A.R.D.) Satellite at Florida Atlantic University

Department of Exceptional Student

Boca Raton, Florida 33431

January 2000 - Present

Assignments include conducting educational programming evaluations for children with autism and related disabilities in school settings as well as private homes. Train and consult with professionals and parents to 
assist with effective programming for children with autism and related disabilities.

Teacher of Students with Disabilities

Miami - Dade County Public Schools

August 1996 to January 2000

North Miami Beach Senior High School

Taught students with varying

exceptionalities in American History, World History, and Reading. Facilitate mainstream meetings with general education teachers. Participate in Individual Educational Plan (IEP) meetings to develop student's yearly academic and behavioral plan. Facilitate Best Buddies Club.

Principal: Ray Fontana

Professional Associations

1996 - Present

Council for Exceptional Children

- Division for Learning Disabilities

- Council for Children with Behavior Disorders

2000 - Present

TASH

2001 - Present

Association for Behavior Analysis 